Federal Reserve Bank of New York
Staff Reports

\title{
Betting against Beta (and Gamma) Using Government Bonds
}

\author{
J. Benson Durham
}

Staff Report No. 708

January 2015

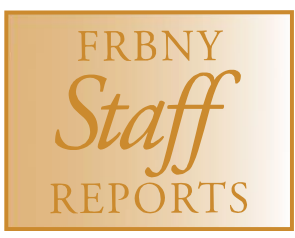

This paper presents preliminary findings and is being distributed to economists and other interested readers solely to stimulate discussion and elicit comments. The views expressed in this paper are those of the author and do not necessarily reflect the position of the Federal Reserve Bank of New York or the Federal Reserve System. Any errors or omissions are the responsibility of the author. 


\author{
Betting against Beta (and Gamma) Using Government Bonds \\ J. Benson Durham \\ Federal Reserve Bank of New York Staff Reports, no. 708 \\ January 2015 \\ JEL classification: G10, G12, G15
}

\begin{abstract}
Purportedly consistent with "risk parity" (RP) asset allocation, recent studies document compelling "low risk" trading strategies that exploit a persistently negative relation between Sharpe ratios (SRs) and maturity along the U.S. Treasury (UST) term structure. This paper extends this evidence on betting against beta with government bonds $\left(\mathrm{BAB}_{\mathrm{gov}}\right)$ in four respects. First, out-of-sample tests suggest that excess returns may have waned somewhat recently and that the pattern seems most pronounced for USTs given data on ten other previously unexamined government bond markets. Second, $\mathrm{BAB}_{\mathrm{gov}}$ appears robust when hedged ex-ante against covariance with equities and thereby does not resemble selling volatility, but these results nonetheless belie a possible tension rather than consistency between leverage constraints and lowrisk investing: namely, that investors bid longer-dated UST prices higher (lower) under BAB (RP). Third, the fact that Gaussian affine term structure models of USTs also imply an inverted SR schedule suggests that investors cannot, in fact, realize abnormal returns if they are fully hedged to the underlying model factors, and $\mathrm{BAB}_{\mathrm{gov}}$ excess returns are indeed not robust to exante constraints on exposure to the yield curve's principal components. Fourth, some evidence suggests that previous $\mathrm{BAB}_{\text {gov }}$ results reflect coskew preferences, alternative $\mathrm{BAB}_{\mathrm{gov}}$ strategies hedged to coskew risks ex-ante forgo substantial returns, and there is no indication that investors can earn excess returns betting against gamma. However, the sign of investors' coskew preferences in government bond markets remains ambiguous.
\end{abstract}

Key words: asset pricing, term structure, risk parity, betting against beta

Durham: Federal Reserve Bank of New York (e-mail: jbenson.durham@ny.frb.org). The author thanks seminar participants at the Federal Reserve Bank of New York for helpful comments. The views expressed in this paper are those of the author and do not necessarily reflect the position of the Federal Reserve Bank of New York or the Federal Reserve System. 


\section{Introduction}

Mounting evidence suggests that low-risk investing delivers superior results, notably both across asset classes, in the context of risk parity (RP), as well as within them, so-called "betting against beta" (BAB). Such findings contradict the intuitive notion that higher expected as well as realized returns compensate investors for taking risk, at least as measured by the second moment of asset returns. The effectiveness of these investment strategies reflects a persistently inverse relation between Sharpe ratios (SRs) and beta, defined as the covariance of asset returns with market portfolio returns, and correspondingly, an insufficiently upwardsloped security market line (SML). Besides a comprehensive study of several asset classes that documents these patterns (Frazzini and Pedersen, 2014), subsequent research reports that excess returns from BAB using global equities are robust not only to size and momentum but also to industry classifications (e.g., Asness et al., 2014).

Even though studies have long noted the modest slope of the SML (e.g., Black, 1972; Black et al., 1972), which is surprising through the lens of the standard two-moment CAPM, the empirical literature on low-risk investing seems far less extensive compared to other anomalies such as value, size, and momentum. Moreover, arguably further analyses of any financial market anomaly tend to gravitate disproportionately to risky assets, shares in particular. ${ }^{1}$ However, BAB results for the U.S. Treasury (UST) market (BAB gov) are among the most compelling, as only three of 28 other BAB strategies across asset classes have higher SRs, ${ }^{2}$ and the $\mathrm{SR}$ for $\mathrm{BAB}_{\text {gov }}, 0.81$, is after all just as large if not greater in fact than that reported for U.S. equities, 0.78 (Frazzini and Pedersen, 2014). ${ }^{3}$ Given these compelling findings, analyses of low-risk investing might evolve with equivalent attention to fixed income instruments, ${ }^{4}$ but to date this literature seems silent on just why low-risk investing works for government bonds, the default-risk-free asset class, as distinct from the mechanisms behind equity market behavior. Whatever the asset class, BAB should work as long as SRs decrease in beta, and the salient features of the historical UST term structure data do seem amenable to the strategy. 5

Just why might compensation per unit of risk decline with maturity and thereby make $\mathrm{BAB}_{\text {gov }}$ strategies profitable for investors who are willing and able to lever? The motivation for additional analyses of $\mathrm{BAB}_{\text {gov }}$ transcends the obvious relevance for investors, and low-risk excess return patterns are noteworthy for

\footnotetext{
${ }^{1}$ Compare the number of studies on, say, momentum in equity as opposed to bond markets.

${ }^{2}$ Frazzini and Pedersen (2014) do not examine non-UST government bond markets.

${ }^{3}$ Note, however, that the sample for equities (USTs) begins in 1926 (1952). Also, the corresponding excess return for $\mathrm{BAB}_{\text {gov }}$ is 17 bps per month (Frazzini and Pedersen, 2014, Table 6, pg. 14), compared with 70 bps for BAB using U.S. equities (Table 3 , pg. 13), again given a longer sample for stocks.

${ }^{4}$ Early indications seem consistent with prior patterns. For example, Baker et al. (2011), Asness et al. (2014), Chow et al. (2014), and Walkshäusl (2014) exclusively address the low-risk anomaly or BAB in the context of equities.

${ }^{5}$ Duffee (2010), Fama and French (1993), and Campbell and Viceira (2001) each document high (low) SRs at the short (long) end of the curve.
} 
monetary policymakers in at least two respects. First, a key mechanism underlying BAB excess returns are leverage constraints, which have obvious implications for broader financial conditions. This notion advances Black's (1972) relaxed CAPM with restricted borrowing and suggests that a sufficient number of individual as well as institutional investors, who notably seek high returns, are limited in their ability to borrow. These restrictions thereby bid up prices on high-beta assets, concomitantly lower required returns, and flatten the SML. BAB ${ }_{\text {gov }}$ patterns in particular highlight not the general level per se but the schedule of (relative) term premiums across yield curves, an arguably neglected subject that can be relevant to market monitoring as well as central bank open market operations. For example, the schedule of forward term premiums, or perhaps rather SRs, seems highly relevant to central banks that endeavor to "remove duration risk" most efficiently from financial markets with outright purchases of government bonds. ${ }^{6}$

Second, the underlying empirical regularity—again, elevated SRs at the front end of the term structure-may represent a puzzle if not an affront to central bankers who painstakingly hone their communication strategies. Investors might not only chronically require greater compensation per unit of volatility around business cycle fluctuations but also amid corresponding uncertainty about the response of monetary policy, quite possibly to varying degrees over time and across space. Therefore, the extent to which SRs are greater at shorter maturities might be assessed in a similar vein as, for example, evidence that distanthorizon forward rates are excessively sensitive to macroeconomic news announcements (Gürkaynak et al., 2005), a finding that arguably reflects unanchored expectations around central bankers' objectives. Evidence on $\mathrm{BAB}_{\text {gov }}$ or simple analyses of $\mathrm{SRs}$ detailed further in subsequent sections below may be relevant in this context. A reasonable prior might be that more inverted SR schedules correspond to less tightly moored expectations around monetary policy goals or, perhaps more accurately, nearer-term objectives. Excess BABgov returns, then, conceivably represent compensation for policy-related risks.

In addition to this shared relevance for investors and policymakers alike, four lingering questions motivate an exclusive, closer look at $\mathrm{BAB}_{\mathrm{gov}}$. The first issue is the simple but pressing imperative to test $\mathrm{BAB}_{\text {gov }}$ out of sample, which includes some further analyses of the U.S. data, including additional focus on time-variation of returns, as well as an extension to 10 other previously unexamined government bond markets, including Germany, France, Netherlands, Belgium, Italy, Spain, Japan, UK, Canada, and Switzerland. Beyond assessing the breadth of the strategy, the cross-sectional evidence may help uncover conditional information relevant to more efficient $\mathrm{BAB}_{\text {gov }}$ strategies.

The second issue stems from the general notion that the mechanisms that drive BAB may fundamentally differ across asset classes, with possible implications for the broader, aggregate issue of RP. Again, Frazzini and Pedersen (2014), drawing on Black (1972), argue that leverage aversion primarily

${ }^{6}$ See, say, Bernanke (2010). 
generates the results. This mechanism seems persuasive within risky asset classes, but leverage aversion with respect to government bond investors may appear at odds with RP itself, given the unique role of the (global) risk-free asset class in portfolios. ${ }^{7}$ To consider any tension between BAB and RP, as well as to evaluate flights-to-quality (FTQs) more broadly as an alternative or complementary explanation for $\mathrm{BAB}_{\text {gov }}$, the following further examines the covariance of $\mathrm{BAB}_{\text {gov }}$ not vis-à-vis the within-asset-class beta but with respect to benchmarks that include the yardstick risky asset class.

Whereas additional evidence on $\mathrm{BAB}_{\text {gov }}$ covariance addresses possible mis-specification broadly reminiscent of the Roll (1977) critique, a third issue regards potential under-specification. Gaussian affine term structure models (GATSMs), a more common asset-pricing framework for government bonds than the $\mathrm{CAPM}$ after all, nest $\mathrm{BAB}_{\text {gov }}$ but hardly imply that returns are anomalous. Closed-form solutions to GATSMs are flexible enough to capture the inverted schedule between SRs and maturity (e.g., Duffee, 2010), without the (however persuasive) amendments to the CAPM based on leverage aversion in Frazzini and Pedersen (2014). The problem for $\mathrm{BAB}_{\text {gov }}$ as a proper anomaly is that GATSM-implied hedge ratios by construction outlaw arbitrage and therefore excess returns, apart from portfolios formed from model-implied fitting errors (e.g., Duarte et al., 2006). Levered portfolios that are long low-betas based solely on the inverted SR schedule, and comprehensively hedged with respect to the underlying model factors, simply cannot produce a free lunch. Perhaps no GATSM calibration comprises a satisfactory test given estimation issues such a parameter stability and sample selection, but the affine model framework readily raises the suspicion that any anomalous aspects of $\mathrm{BAB}_{\text {gov }}$ returns derive from an under-specified pricing kernel. Simple regressions of ex-post $\mathrm{BAB}_{\text {gov }}$ returns on the principle components (PCs) of the term structure as well as returns on portfolios that hedge broader exposure to PCs ex-ante are informative on this score.

The fourth issue addresses the fact that the "risk" in "low-risk investing" refers to the second and not the third moment of asset returns. Beyond leverage aversion theory and other mechanisms, the following examines whether $\mathrm{BAB}_{\text {gov }}$ returns owe in part to investors' coskew preferences. Persuasive behavioral arguments that might account for low-risk patterns for equities, including "over-confidence" and “representativeness," seem much less relevant for bonds. Nonetheless, $\mathrm{BAB}_{\text {gov }}$ portfolios may have demonstrably favorable coskew characteristics that command a (negative) premium, which in turn may help account for the low-second-moment risk phenomenon. Correspondingly, constrained $\mathrm{BAB}_{\text {gov }}$ strategies that neutralize coskew exposures may generate lower returns. And, just as leverage-constrained investors may reach for yield and thereby bid up prices to earn second-moment-based premiums, to boost gains they may

\footnotetext{
${ }^{7}$ See also Adrian et al. (2014), the first study to conduct cross-sectional asset pricing tests that directly include in the pricing kernel measures of leverage, namely from financial intermediary balance sheet data from the Federal Reserve's Flow of Funds data.
} 
similarly pressure required returns on assets with greater coskew risks lower. This begs the question of whether investors can earn excess returns betting against gamma with government bonds (BAG $\left.\mathrm{gov}_{\mathrm{g}}\right)$.

\section{Data and Empirical Design}

These empirical analyses start with a brief evaluation of previous findings using Center for Research in Security Prices (CRSP) data on USTs. Minor tweaks to Frazzini and Pedersen (2014) include use of daily in addition to monthly data (as they do for stocks), market-capitalization-based instead of equal weights across maturities, and alternative windows for estimation of the ex-ante (rolling) betas of 12 and 36 (12 and 59) months for the daily (monthly) frequency. The results also consider alternatives for shrinking the betas, following Vasicek (1973), ${ }^{8}$ although the close relation between beta and maturity (and duration), as well as less suspected measurement error of maturity, may suggest less need to make these adjustments for government bonds. Also, the relevant betas are based on an aggregation of individual CUSIPs from the CRSP data into eight maturity categories, which very closely but not precisely follows Frazzini and Pedersen (2014, Table 5, pg. 14).9

Subsequent sections below examine strategies based on linear programming and non-linear optimizations with key constraints, but the formation of the $\mathrm{BAB}_{\text {gov }}$ portfolios for this section follows the convention introduced in Frazzini and Pedersen (2014), as in

$$
r_{t+1}^{B A B_{g v v}}=\frac{1}{\beta_{t}^{L}}\left(r_{t+1}^{L}-r_{t}^{f}\right)-\frac{1}{\beta_{t}^{H}}\left(r_{t+1}^{H}-r_{t}^{f}\right)
$$

where $r_{t+1}^{L(H)}=\left(r_{t+1}\right)^{T} w_{L(H)}$ and $\beta_{t}^{L(H)}=\left(\hat{\beta}_{t}\right)^{T} w_{L(H)}$, with $r\left(\hat{\beta}_{t}\right)$ the column vector of returns (betas) for each maturity, and $f$ is the risk-free rate (i.e., the one-month bill rate), as defined in Frazzini and Pedersen (2014) and in turn Asness et al. (2014). ${ }^{10}$ All in all, daily (monthly) information is available for a sufficient cross

${ }^{8}$ The shrinkage factor from Vasicek (1973) follows

$$
\hat{\beta}_{i}=w_{i} \hat{\beta}_{i}^{T S}+\left(1-w_{i}\right) \hat{\beta}^{X S}
$$

with

$$
w_{i}=1-\sigma_{i, T S}^{2}\left(\sigma_{i, T S}^{2}+\sigma_{X S}^{2}\right)^{-1}
$$

where $\sigma_{i, T S}^{2}\left(\sigma_{X S}^{2}\right)$ is the time-series, TS, (cross-sectional, $X S$ ) variance of the estimated betas. Frazzini and Pedersen (2014) cite this formula but fix $w_{i}=0.6$, based on their results on U.S. equity data, and set $\hat{\beta}^{X S}=1$ for all assets, including USTs.

${ }^{9}$ As noted in Table 2, these include 1 month to 9 months, 9 months to 2 years, 2 to 3 years, 3 to 4 years, 4 to 5 years, 5 to 6.5 years, 6.5 years to 12 years, and $12+$ years. Varying UST issuance patterns present some challenges for covering some maturity buckets over extended periods. For example, the Treasury issued no 30 -year bonds from November 1978 through February 1985.

10 Also, 
section of maturities from June 1961 (October 1957) through December 2013.11 Assuming a 12-month lag to calculate $\beta_{t}^{L(H)}$ based on daily (monthly) data, the first observation — the estimate of $\mathrm{BAB}_{\text {gov }}$ following (1) for June 1962 — is based on returns from June 1961 through May 1962. The final observation, December 2013, refers to estimates of $\beta_{t}^{L(H)}$ derived from returns observed from December 2012 through November 2013. This produces a total of 620 months.

As noted previously, with the obvious motivation to explore the breadth of the strategy, the analyses cover 10 additional government bond markets and use zero-coupon yield curves from Bloomberg. ${ }^{12}$ These (monthly) data are only comprehensively available from around the mid-1990s, and therefore the inferences additionally comprise out-of-sample temporal tests to a considerable degree. ${ }^{13}$ Also, the international panel evaluates a broader scope of maturities, ${ }^{14}$ notably beyond the 10 -year-plus category in Frazzini and Pedersen (2014) to include the 20- and 30-year sectors in each case for a finer parsing of higher-beta maturities. ${ }^{15}$

\section{Results: Sensitivity Analyses}

These modest revisions to the empirical design produce results that are largely consistent with Frazzini and Pedersen (2014) with respect to USTs. Table 1 reports the results based on daily and monthly returns using CRSP data, with and without shrinkage of the betas, and alternative lag lengths for estimation of the betas, namely one and three years for daily data and one and five years for monthly data. Without exception across these eight specifications, the $\mathrm{SRs}$ for $\mathrm{BAB}_{\text {gov }}$ exceed those on the UST index as well as the stock market, and the excess returns in some cases are greater than those on shares. Although the results using 1-year lags based on either daily or annual returns are less pronounced, the magnitude of the findings

$$
w_{L(H)}=k(z-\bar{z})^{-(+)}
$$

where $k=2\left(1_{n}^{\prime}|z-\bar{z}|\right)^{-1}, z=\operatorname{rank}\left(\beta_{i t}\right), 1_{n}$ denotes a vectors of ones of length $n$, and $x^{+(-)}$indicate the positive (negative) elements of the vector $x$.

${ }_{11}$ Note that the results below refer only to monthly data from June 1961 to ensure consistency with the estimates based on daily data. However, earlier data do not meaningfully change the inferences.

${ }^{12}$ Longer time series of fitted yield curves exist for a few cases, but Bloomberg perhaps provides the most comprehensive coverage for the purpose of consistent comparisons.

13 The Bloomberg (Index) mnemonics for, say, 10-year yields, are C91010Y (Germany), C91510Y (France), C92010Y (Netherlands), C90010Y (Belgium), C90510Y (Italy), C90210Y (Spain), C10510Y (Japan), C11010Y (UK), C10110Y (Canada), C25610Y (Switzerland), and C08210Y (U.S.).

${ }^{14}$ To estimate realized returns on, say, the 10-year zero, further spline-based estimates of 9-year, 11-month zero-coupon yields are required, and the calculations otherwise follow Adrian et al. (2013). In addition, market capitalization weights are unavailable, and therefore the estimates of market returns assume equal weight across maturities, following Frazzini and Pedersen (2014).

${ }^{15}$ Note also that Frazzini and Pedersen (2014) do not report data on the longest maturity bonds from August 1962 to December 1971. Also, lengthening the cross-section with finer delineations of duration might be very useful for assetpricing tests. 
based on longer lags are similar to Frazzini and Pedersen (2014). For example, as noted in Table 1 as well as Figure 1, daily data based on shrunk betas estimated with a 3-year lag, which implies 596 months of returns from May 1964 through December 2013, produce an average (calendar-time, daily) excess return (SR) of about 4.0 basis points (bps) (1.01), compared to $2.7 \mathrm{bps}(0.47)$ for the UST market and $4.0 \mathrm{bps}(0.19)$ for equities. The long (short) side of the strategy on average has a beta of about 0.43 (1.85) or concomitantly a required leverage ratio of 2.35 (0.54), and the ex-post beta (alpha) is very close to zero (positive), as expected and consistent with Frazzini and Pedersen (2014). These results, in turn, reflect a clear underlying negative relation between SRs (alpha) and maturity, which declines from about 1.359 (0.00017) to $0.214(-0.00029)$ from the $1 \mathrm{M}-9 \mathrm{M}$ to the $10 \mathrm{Y}+$ maturity category, as noted in the top panel of Table 2 .

Beyond this corroboration of previous results, time variation in $\mathrm{BAB}_{\text {gov }}$ returns merits further consideration. Figure 1 also shows the rolling (geometric) 5-year mean return from the strategy, the black line, which is notably lower toward the end of the sample and approaches zero, and indeed the SR from 1992 decreases to 0.74 from 1.01. Although not necessarily indicative of a "vanishing" or disappearing" anomaly per se, a reasonable prior is that the results might not be as compelling for the cross-section of 10 other markets, given that data are only available from the 1990s. Indeed, as noted in the last column of Table 3, the corresponding Bloomberg data for the US (considering the 36-month estimation lag length for beta), which again are monthly and also include the 20- and 30-year sectors, produce a lower SR (0.353) over the January 1995 to November 2014 sample. Then again, the returns to $\mathrm{BAB}_{\text {gov }}$ based on these limited Bloomberg data nonetheless suggest a comparatively profitable strategy, as the SRs during this particular sample for the UST and equity markets, as well as for a balanced portfolio, ${ }^{16}$ are clearly lower at $0.161,0.129$, and 0.196, respectively. In addition, excess $\mathrm{BAB}_{\mathrm{gov}}$ (calendar-time, monthly) excess returns are $61.6 \mathrm{bps}$, compared to 29.7, 57.4, and 43.6 bps, respectively.

However, the same cannot be said as assuredly for a number of other markets, and therefore the results to $\mathrm{BAB}_{\text {gov }}$ may be somewhat sensitive to not only temporal but also spatial out-of-sample tests. Table 3 also reports that $\mathrm{BAB}_{\text {gov }}$ has a lower (greater) SR than the local government bond (stock) market in each of the 10 cases. Also, $\mathrm{BAB}_{\text {gov }}$ excess returns exceed those on the corresponding equally-weighted government bond in all cases except Canada, but the differences are arguably minimal compared to the U.S., with perhaps the lone exception of data on Japan, which produces an excess return on $\mathrm{BAB}_{\text {gov }}$ of $50.2 \mathrm{bps}$, compared to 20.1 bps on the constructed government bond index over the sample. Also, $\mathrm{BAB}_{\mathrm{gov}}$ excess returns are greater than those on shares for six of the 10 non-U.S. cases-Germany, France, Netherlands, Belgium, Italy, and

\footnotetext{
16 The balanced portfolio is an equally-weighted average of returns on the local stock market, measured by the MSCI local currency, gross total return index (e.g., GDDU), and the government bond index, in turn an equally-weighted average of the 10 maturity points, which include 3 and 6 months as well as 1,2, 3, 5, 7, 10, 20, and 30 years. The Bloomberg country (Index) codes follow GR (Germany), FR (France), NE (Netherlands), BE (Belgium), IT (Italy), SP (Spain), JN (Japan), UK (United Kingdom), CA (Canada), SZ (Switzerland), and US (United States).
} 
Spain-but on balance, these results seem to contrast meaningfully with those of the U.S., even allowing for the differing temporal coverage of the CRSP and Bloomberg data. Furthermore, this general inference is insensitive to assumptions regarding lag lengths, namely for 12- and 60-months, in addition to the 36-month length for beta estimations summarized in Table 3 .

To consider some explanations for the discrepancy, again $\mathrm{BAB}_{\text {gov }}$ profitability rests on a downwardsloping schedule of SRs along the term structure, and as Figure 2 indicates, this pattern seems common but perhaps not universal given this cross section of government bond markets. The schedule for the U.S., assigned to the back of the surface, is the most clearly downward sloping, but Germany, say, positioned at the front, displays a noticeably less pronounced but nonetheless consistent pattern. In addition, Figure 3 corresponds to Figure 2 but focuses on comparisons with Germany, Japan, the U.K, and Switzerland and shows a similarly inverse but weaker relation compared to the U.S. along the curve, which in turn reflects less compelling $\mathrm{BAB}_{\text {gov }}$ excess returns. ${ }^{17}$ This cross-sectional evidence may be constructive in identifying thresholds that signal abnormal $\mathrm{BAB}_{\text {gov }}$ returns, but the results also may motivate a closer examination of the transmission mechanisms relevant for $\mathrm{BAB}_{\text {gov }}$, or perhaps USTs in particular as a distinct global asset class.

\section{More on Covariance: From FTQs to tension between BAB and RP}

Indeed, the dearth of compelling evidence across other government bond markets might reflect unique demand for longer-dated \$U.S. denominated assets that transcends any leverage mechanism. Insofar as longer- as distinct from shorter-dated USTs benefit from (global) safe-haven flows, or more precisely provided investors anticipate this safe-haven demand, $\mathrm{BAB}_{\text {gov }}$ returns may owe less to leverage constraints per se. In fact, some studies find that GATSM-based term premiums are negatively correlated with the VIX (Li and Wei, 2012; Durham, 2008), or that jointly-estimated term and equity risk premiums are negatively correlated (Durham, 2013a), findings that at first blush suggest that $\mathrm{BAB}_{\text {gov }}$ returns should be lower precisely during "bad times." 18 However, this is only true if decreases in term premiums, notably scaled by risk, are greater at the back end of the term structure. The results may hinge on investors' perceptions and expectations of the severity of shocks - during more benign FTQs, investors shed credit but not duration exposure, whereas during more severe shocks they jettison both credit and duration risk for the relative safety of short-dated government paper. The former (latter) would suggest that BAB does (does not) indeed

\footnotetext{
${ }^{17}$ Higher SRs at the very front end of the US as opposed to other sovereign curves may owe more to the numerator rather than the denominator. At the very front end of the term structure, perhaps surprisingly, greater returns are a substantial part of the story, however further out the yield curve it appears that greater U.S. volatility plays the larger role.

${ }^{18}$ Ilmanen (2011) argues that BAB returns resemble the profile of volatility selling, which pays off in "good" rather than "bad times."
} 
resemble volatility selling. ${ }^{19}$ In any case, practitioners might worry that by underweighting the long end, $\mathrm{BAB}_{\text {gov }}$ foregoes meaningful insurance against risky assets, and therefore excess returns reflect compensation for such exposure. ${ }^{20}$

More broadly, the single-factor asset-pricing model behind previous $\mathrm{BAB}_{\mathrm{gov}}$ results is possibly misspecified, perhaps broadly reminiscent of the Roll (1977) critique, not because the relevant market is unobservable but rather given that the narrow within-asset-class betas behind $\mathrm{BAB}_{\text {gov }}$ exclude information about covariance with the risky asset class. Two sets of rudimentary estimates are informative. The first is simply to examine $\mathrm{BAB}_{\text {gov }}$ return loadings with respect to broader portfolios, $\Pi$, including, first, an marketcapitalization-weighted index of USTs and stocks from the CRSP dataset and, second, a pure equity portfolio, as in

$$
r_{t}^{B A B_{g n}}=\alpha+\beta^{\Pi} r_{t}^{\Pi}+\varepsilon_{t}
$$

Table 2 also lists these results, namely the ex-post betas with respect to both measures of $\Pi$ for $B B_{\text {gov }}$ as well as the eight maturity buckets, alongside the corresponding beta for the UST market index with respect to $\Pi$. In short, $\mathrm{BAB}_{\text {gov }}$ appears to hedge against the balanced and equity portfolios just as well as, if not better than, any sector of the term structure or the market as a whole. Both relevant betas are negative $(-0.0054$ and -0.0041), whereas the remaining estimates along the term structure (from the 1-9 month to the 12-year pluse categories) are strictly positive, albeit similarly close to zero. Of course, a covariance matrix might also suffice, but these simple loadings seem inconsistent with the view that broader FTQs produce BAB gov excess returns.

The second constructs an alternative $\mathrm{BAB}_{\text {gov }}$ trading strategy that similarly levers (de-levers) the long(short-) side to have a beta of one as in Frazzini and Pedersen (2014), but under the linear programming constraint that the long side has no greater beta with respect to, alternatively, the balanced or the pure equity portfolio than the short side of the trade. More formally, the objective function and constraint follow

$$
\begin{gathered}
\min _{\left\{w_{L}^{*}\right\}}\left[\left(w_{L}^{*}\right)^{T} \hat{\beta}_{t}\right] \\
\text { s.t. } \\
\left(w_{L}^{*}\right)^{T} \hat{\beta}_{t}^{\Pi} \leq\left(w_{S}^{*}\right)^{T} \hat{\beta}_{t}^{\Pi}
\end{gathered}
$$

\footnotetext{
${ }^{19}$ Peso problems may lurk in the background, as it could be that even during a lengthy sample mild FTQs obtained, increasing the demand for longer- relative to shorter-dated Treasuries. What matters for $\mathrm{BAB}$ and leverage aversion is whether investors perceive longer-dated Treasuries as a better hedge against risky assets, which in turn depresses (expected) SRs further out the term structure. Therefore, instead of, or in addition to, leverage aversion, investors with balanced mandates may be paying an insurance premium.

${ }^{20}$ Frazzini and Pedersen (2014) report within-asset-class ex-post BAB betas and do not address whether the long side has covariance properties that command positive premium.
} 
where $\beta_{t}$ is the vector of (UST, within-asset-class) betas along the term structure, the weights for the short side follow $\max _{\left\{w_{s}^{*}\right\}}\left[\left(w_{S, t}^{*}\right)^{T} \beta_{t}\right]$, and $\beta_{t}^{\Pi}$ is the vector of betas with respect to the portfolios that include stock returns. ${ }^{21}$ The returns follow

$$
r_{t+1}^{B A B_{g w}}=\frac{1}{\left(w_{L}^{*}\right)^{T} \hat{\beta}_{t}}\left[\left(w_{L}^{*}\right)^{T} r_{t+1}-r_{t}^{f}\right]-\frac{1}{\left(w_{S}^{*}\right)^{T} \hat{\beta}_{t}}\left[\left(w_{S}^{*}\right)^{T} r_{t+1}-r_{t}^{f}\right]
$$

The resulting portfolio therefore is not only neutral to the UST market beta but also to the short side's covariance with $\Pi . .^{22}$ Put another way, (3) represents BAB, but without decreased relative protection against stock market declines to achieve "low-risk government bond investing, without stock market covariance bets."

Consistent with the simple betas in Table 2 , the results in Table 4 clearly suggest that $\mathrm{BAB}_{\text {gov }}$ does not increase exposure to the yardstick risky asset class, and the results contradict the notion that $\mathrm{BAB}_{\text {gov }}$ owes to FTQ-related preferences for longer-dated USTs. For example, the SRs for the constrained strategy with respect to the balanced (stock) portfolio is 1.22 (1.09), which compares quite favorably with the results of the unconstrained linear programming SRs of about 1.27. Also, the drag on average (daily) excess returns is modest, with returns of $10.1 \mathrm{bps}$ and $8.8 \mathrm{bps}$, compared to the unconstrained portfolio excess returns of 10.6 bps. ${ }^{23}$ Tables 6 and 7, which include the excess returns and SRs, respectively, for the constrained strategies across the 10 additional government bond markets tell similar stories, with only a few exceptions. As such, these results contradict the general notion that $\mathrm{BAB}$ constitutes volatility selling. Instead $\mathrm{BAB}_{\text {gov }}$ appears to pay off just as well as a generic portfolio of USTs in "bad times."

Arguably, these $\mathrm{BAB}_{\text {gov }}$ results constitute further crucial out-of-sample confirmation of RP, which rests on "only one draw from history (though admittedly a fairly long one)," following Asness et al. (2012, pg. 48). However, even if the strategy does not appear to reflect selling volatility, $\mathrm{BAB}_{\text {gov }}$ may still represent a

${ }^{21}$ An equality constraint-e.g., $\left(w_{L}^{*}\right)^{T} \hat{\beta}_{t}^{\Pi}=\left(w_{S}^{*}\right)^{T} \hat{\beta}_{t}^{\Pi}$-is too restrictive. The objective is to insure ex-ante that the $\mathrm{BAB}_{\text {gov }}$ portfolio does not afford less of a hedge than the short side.

22 The linear programming constraint in effect forces the long side to include any sectors of the Treasury curve that hedge covariance at least as well as the short side.

${ }^{23}$ In addition, the short end of the UST curve on average, but not always over the full sample, has a lower covariance with shares. That is, the constraint binds at times, evidenced by the fact that the average beta of the short side is about 0.584 (0.672), compared to the 0.200 average beta for the unconstrained portfolio. Also not the fact that returns are near zero for the most recent five years or so in the sample, when the long-end may have proved a decidedly better hedge with respect to shares near the zero lower bound. (In general, such a constraint is perhaps preferable to the ordinal weighting scheme for the standard $\mathrm{BAB}_{\text {gov }}$ portfolio, insofar as required leverage is much lower. Therefore, investors might consider linear-programming with stock market covariance constraints instead of the somewhat arbitrary weighting scheme in Frazzini and Pedersen (2014), which may exclusively serve to lower leverage requirements by adding relatively higher-beta assets to the long side.) 
special if not problematic case for RP. Consider investors who participate exclusively in the UST market, and make all assumptions consistent with $\mathrm{BAB}$. These participants may well overweigh the back end of the term structure, increasingly so with leverage constraints. Such preferences push prices (yields) on, say, 10-year USTs higher (lower), all else equal. Now consider another set of investors with balanced mandates who participate in both the UST and the U.S. stock market. The same leverage constraints bind, but notably now across rather than within asset classes, as in the broader context of RP. These investors may well overweigh not longer-dated Treasuries but riskier shares to boost returns. Preferences push stock prices higher and expected equity returns lower, but they also may pressure bond prices (expected returns) lower (higher) amid "reaching for yield." Therefore, investors with balanced mandates (and especially those also with longerduration liabilities) may offset those with narrower constraints, and heterogeneous preferences buffet longerdated yields. Without further clarification, BAB says leverage-constrained investors buy UST duration to boost returns, whereas RP implies they sell it to do so, ${ }^{24}$ and the net effect on longer-dated yields appears ambiguous. Unlike $\mathrm{BAB}$ evidence on risky asset classes, $\mathrm{BAB}_{\text {gov }}$ is perhaps not so much any confirmation as a contradiction for RP, absent a complicated untold segmentation story that reconciles heterogeneous investor preferences. ${ }^{25}$

\section{GATSMs and Under-Specification}

Besides mis-specification and tension between $\mathrm{BAB}$ and $\mathrm{RP}$, also consider potential underspecification. That is, although the CAPM and its extensions are common benchmarks for shares, the same cannot be said for government bonds. Instead assess government bond SRs in the context of GATSMs, which after all produce closed-form expressions for SRs (Duffee, 2010). ${ }^{26}$ Again, BAB works if SRs decrease in beta (or duration), and the relevant analytical quantity is simply the partial derivative of SRs with respect to maturity. ${ }^{27}$ Whereas the CAPM must be amended to incorporate borrowing constraints and capture the relation, standard GATSMs do not. With the exception of some simplistic models, such as Merton (1973), ${ }^{28}$ calibrated GATSMs are flexible enough to produce downward-sloping SR schedules with respect to maturity, but notably under conditions that preclude arbitrage. As such, the model parameters, particularly the generic market price(s) of risk, might very well suggest more general mechanisms besides leverage aversion.

\footnotetext{
${ }^{24}$ Indeed, Asness et al. (2012, pg. 49) note that under BAB "safer short-maturity U.S. Treasuries offer higher riskadjusted returns than do riskier long-maturity ones" but "(w)ith respect to RP, bonds are the low-beta asset and stocks the high-beta asset, and the benefit that we documented is another empirical success of the theory."

${ }^{25}$ Baker et al. (2011, pg. 7) note that balanced fund mandates, without leverage constraint as well as perhaps beta rather than a market-weight allocation to shares, conceivably buy low-beta stocks (and presumably longer-dated Treasuries), but they also suggest that such mandates, at about two percent of the total, indeed hardly comprise the "representative investor" capable of realigning asset prices.

${ }^{26}$ A GATSM might have a CAPM representation, but nonetheless the issue is under-specification of the pricing kernel. 27 As Frazzini and Pedersen (2014, pg. 3) note, term premiums exists at all horizons beyond the instantaneous short rate. 28 See Appendix 1.
} 
To repeat, $\mathrm{BAB}_{\text {gov }}$ results are based on a univariate asset-pricing framework (e.g., Frazzini and Pedersen, 2014), but the literature on term structure models ubiquitously considers multiple factors, including not just the level but also the slope and curvature of the term structure as well as other latent as well as spanned and un-spanned macroeconomic factors. Moreover, and unfortunately for the prospects of a free lunch, the observation that estimated GATSMs produce the salient features of the data, including SRs that decline with maturity (Duffee, 2010), hardly confirms but rather precludes excess returns from BAB gov. $_{\text {. }}$ Reconsider a $\mathrm{BAB}_{\text {gov }}$ strategy that is long the front end, $P^{L}$, to exploit elevated GATSM-based SRs, with corresponding short positions, $P S$, of required quantity, $\Delta$, to offset the exposure of the long side to each of the underlying model factors, $x .^{29}$ Instead of levering the long and shorts sides up and down to a beta equal to one, as in (1), the hedge ratios, $\delta_{1}^{s}$ and $\delta_{2}^{s}$, for a 2 -factor model, which can be trivially extended to $n$ factors, follow

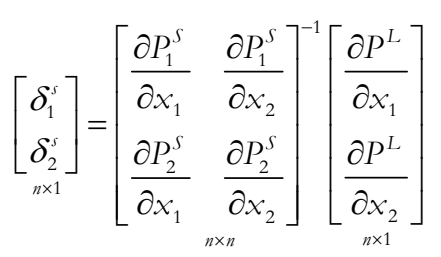

But, these portfolio weights, very much akin to those in, say, Langetieg (1980), produce a certain return that cannot exceed the risk-free rate without arbitrage (and in turn lead to the bond pricing equation). In other words, the relevant partial derivatives on the right hand side of (4) are derived under the no-arbitrage restriction, and therefore $\mathrm{BAB}_{\text {gov }}$ can only work by the coincidence that GATSM-implied yields are persistently lower (higher) than observed yields at the front (back) end of the term structure, or if model fitting errors are somehow a function of maturity. The very fact that GATSMs readily reproduce the required SR schedule suggests that $\mathrm{BAB}_{\text {gov }}$ portfolios ultimately cannot produce excess returns, if comprehensively hedged. Of course, to assert that any anomaly must compensative investors for some unknown but "true risk" is unconstructive, but the issue is that GATSM-implied SRs may question more than confirm BAB gov $_{\text {as }}$ an anomaly per se.

Any empirical illustration of these restrictions, besides comprising a somewhat pedantic exercise, is beset by the fact that arguably no calibration of a GATSM is satisfactory, given estimation issues such a

${ }^{29}$ That is, the portfolio, which includes as many bonds as underlying risks, is $P^{L}+\Delta P^{S}$, with the weights chosen to satisfy

$$
\frac{\partial P^{L}}{\partial x}+\Delta \frac{\partial P^{S}}{\partial x}=0
$$


parameter stability, not to mention sample selection in forming trading strategies. ${ }^{30}$ However, two simple tests with much less structure might address some of the related issues, particularly that the asset-pricing model on which BAB is based is not as much mis-specified, as in the case of covariance with risky assets, as under-specified with respect to the multivariate nature of bond yields. The first is to examine $\mathrm{BAB}_{\mathrm{gov}}$ return loadings on the (first three) principal components of the yield curve, ${ }^{31}$ denoted by the vector $P C_{t}, 32$ following

$$
r_{t}^{B A B_{g o v}}=\alpha^{P C}+\left(\beta^{P C}\right)^{T} P C_{t}+\varepsilon_{t}
$$

Table 2 also includes these results, and notably $\alpha^{P C}(0.0004)$ is safely significant within the 95 percent band and is just as large in magnitude as the corresponding estimate of ex-post $\alpha$ with respect to overall UST market returns (0.00039).33 Moreover, the loadings on each PC are within the range of estimates of the corresponding ex-post betas for the eight sections of the yield curve, and therefore $\mathrm{BAB}_{\text {gov }}$ appears to be robust, with no increased (contemporaneous) exposure to the underlying factors of the term structure.

However, a second test is more punishing and comprises an alternative $\mathrm{BAB}_{\mathrm{gov}}$ trading strategy that similarly levers (de-levers) the long- (short-) side based on the beta with respect to the UST market, but under the constraint that the long and short sides have equivalent exposure to UST market PCs, following

$$
\begin{gathered}
\min _{\left\{w_{L}^{*}\right\}}\left[\left(w_{L, t}^{*}\right)^{T} \hat{\beta}_{t}\right] \\
\text { s.t. } \\
\left(w_{L, t}^{*}\right)^{T} \hat{\beta}_{t}^{P C}=\left(w_{i, t}\right)^{T} \hat{\beta}_{t}^{P C}
\end{gathered}
$$

where $\hat{\beta}_{t}^{P C}$ is the $n \times m$ matrix of ex-ante beta exposures across the term structure to the first $m$ PCs estimated from $t-s$ to $t-1, w_{i, t}$ is the market weight of the $i^{t h}$ of $n$ maturity categories at time $t$, and returns, then, generally follow (4). ${ }^{34}$ The lower panels of Table 4 include the results for three constraints, including

\footnotetext{
${ }^{30}$ In other words, one could examine whether the gap between GATSM-based fitted and observed yields-i.e., violations of the no arbitrage restriction-decline with duration, but uncertainty around parameter estimation and sample selection would complicate inferences from such an investigation.

${ }^{31}$ Duffee (2010, pg. 3) suggests that GATSMs attribute the downward-sloping SRs to "level' and "slope" risk. That is, "investors are compensated for the risk that the term structure jumps up; all bonds face this risk. Investors are also compensated for the risk that that slope of the term structure falls. Long maturity bonds hedge this risk, while shortmaturity bonds are exposed to this risk." If so, exposure to slope risk in particular might account for $\mathrm{BAB}_{\text {gov }}$ returns given the underweight to the back end of the yield curve.

32 The PCs are derived from 1-, 2-, 3-, 4-, 5-, 10-, 20-, and 30-year fitted zero-coupon yields over the full sample based on Gürkaynak et al. (2007).

${ }^{33}$ Table 2 assigns 0 to alpha estimates within the 95 percent confidence interval.

${ }^{34}$ That is, the PC betas for maturity category $i$ follow
} 
slope (S); slope and curvature (S-C); and level, slope, and curvature (L-S-C). The SR for the strategy with the slope beta constraint (0.387) is favorable with respect to either the stock or the UST market, but the figure is much lower than that for the unconstrained BAB strategy (1.27), with substantially lower returns, 1.4 bps compared to $10.6 \mathrm{bps}$ ( $4.0 \mathrm{bps}$ for the standard strategy). The tighter constraints that include curvature as well as level exposure produce minimal excess returns, $0.4 \mathrm{bps}$ and $0.2 \mathrm{bps}$, respectively, and unremarkable SRs. In addition, the cross-sectional evidence similarly suggests that PC-based constraints are punitive, as the SRs listed in Table 6 under the S, S-C, and L-S-C constraints are negligible. Tellingly also, the weighted betas of the long sides given ex-ante hedges for slope and curve- not to mention for the level, slope, and curveincreasingly approach unity, which may simply suggest that investors cannot simultaneously $\mathrm{BAB}$ and hedge these PCs to meaningful effect. Thus in short, although ex-post $\mathrm{BAB}_{\mathrm{gov}}$ returns do not seem to load on contemporaneous PCs, ex-ante hedges against exposure to the underlying PCs appear very costly, which in turn raises questions about under-specification. Yet whatever these empirical results, again GATSM-implieddownward-sloping SR schedules do not necessarily imply excess $\mathrm{BAB}_{\text {gov }}$ returns.

\section{Skew Preferences}

The previous discussion of mis- and under-specification is confined to "risk" with respect to the second moment of returns. Another consideration regarding $\mathrm{BAB}$ in general as well as $\mathrm{BAB}_{\text {gov }}$ in particular is investors' skew preferences, ${ }^{35}$ which might but need not necessarily stem from managerial delegation. ${ }^{36}$ Indeed, the literature on third-moment preferences with reference to flat SMLs and high risk-adjusted returns on low-second-moment-risk assets is hardly new. As Kraus and Litzenberger (1976) reported in their early study of the three-moment CAPM, higher beta portfolios exhibit greater market coskew, which in turn requires a premium that might account for the lower-than-expected second-moment-based slope of the

$$
r_{i, t}=\alpha_{i}^{P C}+\left(\beta_{i, t}^{P C}\right)^{T} P C_{t}+\varepsilon_{i, t}
$$

where $t$ refers to the alternative lagged windows. An ex-ante slope beta, for example, is the coefficient on the regression of, say, 2- to 3-year maturity returns on the second PC of the yield curve, estimated over the, say, 12-month rolling window.

35 Another possible explanation for abnormal returns on low-risk assets refers to delegated management incentives, namely benchmarking (Baker et al., 2011), arguably representative of a broad limit to arbitrage. Although absolute risk, or rather covariance with marginal utility, should matter for investors, typical industry practice is to assess managerial skill with respect some benchmark. In turn, although low-risk strategies produce quite favorable SRs, information ratios (IRs) may pale in comparison, and therefore even "smart" managed money does not offset the price impact of (irrational) demand for high-beta assets.

${ }^{36}$ More recently, Taleb (2004) makes the opposite case for negative skew preferences, but only partially in the context of delegated asset managers who prefer "blowups" over "bleeding." To the extent that the representative investor conforms to utility functions broadly consistent with prospect theory, the agent-based mechanisms that Baker et al. (2011) describe are neither necessary nor sufficient conditions for BAB. 
SML.37 Expected excess returns, $E\left\{r_{i}^{e}\right\}$, are a function of not only covariance with market portfolio returns but also coskew, with $\lambda_{\gamma}<0$, as in

$$
E\left\{r_{i}^{e}\right\}=\lambda_{\beta} \hat{\beta}_{i}+\lambda_{\gamma}\left[\hat{\gamma}_{i} \times \operatorname{sign}\left(M_{m}^{3}\right)\right]
$$

where $\gamma$ follows

$$
\hat{\gamma}_{i}=\frac{\operatorname{cov}\left\{r_{i}\left(r_{m}-\mu_{m}\right)^{2}\right\}}{E\left\{\left(r_{m}-\mu_{m}\right)^{3}\right\}}
$$

and $M_{m}^{3}$ is the third central moment of market returns. ${ }^{38}$ Kraus and Litzenberger (1976) posit that high beta is a source for gamma, ${ }^{39}$ and as such $\mathrm{BAB}$ might seem less anomalous in the context of a higher-moment CAPM.40 Thus, low-risk investing with respect to the second moment of returns might comprise high-risk investing regarding the third, and the literature does not address whether $\mathrm{BAB}_{\text {gov }}$ might embed coskew risks. ${ }^{41}$

Even so, much of the intuition for skew preferences for risky asset classes seems less germane to government bonds, given the usual focus on the potential for exceptional upside rather than downside protection. For example, Mitton and Viorkink (2007) find that volatile stocks are more positively skewed, and therefore command higher prices, owing to their lottery-like potential cash flows. To a large degree, these mechanisms stem from "representativeness," which hardly seems relevant to longer-dated Treasuries that may benefit from FTQs. Consider also the literature that invokes "overconfidence" in the context of skew. Diether et al. (2002) argue consistent with Miller (1977) that, given impediments to short selling,

\footnotetext{
37 Transaction costs are another consideration under this general rubric, and indeed bid-ask spreads can be particularly punitive at the very short end of the UST bill curve (Duffee, 2010), again where the long side of BAB Treasury portfolios are notably overweight. But at the same time, as Duffee (2010) and Figure 4 illustrate, the inverse relation between SRs and maturity (or beta) is more monotonic than discontinuous and does not owe exclusively to the front end. In addition, the results in Frazzini and Pedersen (2014) do not rest on exclusively overweighing the shortest maturities, as instead the low and the high beta portfolios include every sector along the term structure, albeit with greater weights on the extremes.

38 See Appendix 2 for rudimentary measurement details.

${ }^{39}$ Kraus and Litzenberger (1976, pg. 1098) regress gamma on beta and report a coefficient greater than unity (i.e., 4.5), and they infer that "investors have an aversion to increases in beta as a direct measure of systematic standard deviation and have a preference for increases in beta as a surrogate for proportionally greater increases in systematic skewness (given positive market skewness)."

40 An analogous explanation for BAB success with respect to shares refers to the observation that high-beta, volatile stocks also tend to be small and illiquid, which presumably in the context of Baker et al. (2011) suggests that institutional investors cannot exploit the anomaly. An alternative reasoning, as the following outlines, is that skew preferences for lottery-like payoffs account for lower expected returns.

${ }^{41}$ Put another way, explicit consideration of the coskew of BAB returns should shed light on the extent to which leverage constraints drive the anomaly, as Ilmanen for example pits leverage constraints and skew preferences as alternative explanations.
} 
optimists' influence over stocks prices increases with uncertainty, evidenced by disagreement among investors. Therefore, volatile high-beta stocks are overbid to the extent optimists disproportionately set prices, again under the assumption that otherwise offsetting investors have a general reluctance or inability to short stocks, notably not inconsistent with leverage aversion. ${ }^{42}$ The same mechanism may work for longerdated Treasuries, but the logic contradicts the documented positive empirical correlation (and analytical result from GATSM closed-form solutions) between uncertainty and term premiums (i.e., required returns over short rates). Convention suggests that greater volatility lowers, rather than increases, expected returns in government bond markets.

Nonetheless, coskew preferences may help account for $\mathrm{BAB}_{\text {gov }}$, but through distinct channels. ${ }^{43} \mathrm{It}$ may seem de rigueur to test whether any fixed-income arbitrage strategy resembles "picking up nickels in front of steamrollers (Duarte et al., 2006)," but more importantly, fixed income securities may have fundamental characteristics that generate asymmetric return distributions, as of course bond prices (nominal interest rates) face an upper (lower) bound at par (zero). In addition, "pull to par" is arguably more pronounced nearer the short end of the term structure, which may be especially relevant for $\mathrm{BAB}_{\text {gov. }}$ In fact, Fujiwara et al. (2013) report conditional negative skew using daily government bond excess returns, particularly at shorter maturities, ${ }^{44}$ which may imply greater second-moment-based SRs at shorter horizons consistent with $\mathrm{BAB}_{\mathrm{gov}}$. Also, Durham (2008) argues that expected returns, as measured by ex-ante GATSMbased term premiums in the U.S., positively correlate with Eurodollar-option-implied short-term-interest-rate skew but does not address the schedule of SRs. ${ }^{45}$ Yet to be sure, coskew rather than unconditional skew should affect asset returns. The question is whether the coskew of longer-dated bonds makes them pay off disproportionately well, again per unit of duration risk, compared to shorter-dated securities in "bad times" amid asymmetric shocks to both the risk-free and the risky asset classes. The coskew of returns-both within the Treasury market, as in the $\mathrm{BAB}$ evidence, or across asset classes, more relevant to $\mathrm{RP}$-may complement

\footnotetext{
42 See Hong and Sraer (2012) also in this general context.

43 The argument is not that the back end of the Treasury curve has (potential) lottery-like return characteristics. But perhaps in contrast to Ilmanen (2011, pg. 389), downside protection from Treasuries might nonetheless manifest through coskew preferences, in addition to volatility, correlation, and jump premiums.

${ }^{44}$ Even so, they also find that the Bowley coefficient, defined in Appendix 2 as a measure of skew nearer the center of the distribution and notably further from the tails, is often positive, which suggests that negative standard skew in the sample owes to outliers (i.e., the small probability of a large and negative excess return).

45 Three-moment CAPM tests for USTs are also informative with respect to the ubiquitous use of GATSM, in which by definition skew cannot be priced.
} 
or supplant leverage aversion theory behind $\mathrm{BAB}_{\text {gov }},{ }^{46}$ as investors may not be so much reaching for yield amid leverage constraints as paying for their preferred coskew exposure. ${ }^{47}$

Two benchmarks for coskew are relevant, which reflects the previous discussion of covariance. The first is within asset classes, to follow Frazzini and Pedersen (2014), and the second is across them, which addresses the notion that skew preferences may operate through broader (balanced) asset allocation channels. From a practitioner's perspective, the question is whether $\mathrm{BAB}_{\text {gov }}$ unwittingly entails coskew risks, with respect to either the UST or the stock market, and toward that end, Table 2 also reports BAB coskew with different tenors along the government bond curve. Considering the UST benchmark first, again to address directly the original $\mathrm{BAB}$ findings, $\gamma$ tends to increase with maturity, not unlike $\beta$, and ranges from an ex-post (ex-ante) estimate of 0.50 (0.87) for the 1-to-9-month category to $1.86(1.40)$ for the longest duration category. Notably, the ex-post estimate is 0.44 for the $\mathrm{BAB}_{\text {gov }}$ portfolio, and the key issue is contribution to unconditional UST market portfolio skew, which is positive according to both standard (0.536) and Bowley skew (0.093) measures. ${ }^{48}$ Therefore, under the conventional assumption that investors prefer positive portfolio skew, $\gamma$ commands a negative premium, ${ }^{49}$ and as such skew preferences may help account for previous $\mathrm{BAB}_{\text {gov }}$ results (Frazzini and Pedersen, 2014), because longer maturities best contribute to the overall positive tilt of UST market returns over this sample.

However, beyond the initial $\mathrm{BAB}_{\text {gov }}$ results, the second broader set of benchmarks imply no clear inference, as the corresponding estimates of $\gamma$ with respect to the broader balanced portfolio of bonds and stocks produce ambiguous relations. $\mathrm{BAB}_{\text {gov }}$ returns have negative coskew with the balanced portfolio (.0572), which has negative unconditional standard (-0.973) as well as Bowley skew (-0.069), and thereby implies a positive premium. Also, the $\gamma$ for $\mathrm{BAB}_{\text {gov }}$ is safely within the range across the term structure (from 0.102 for the $3 \mathrm{Y}-4 \mathrm{Y}$ sector to -0.014 for the $1 \mathrm{M}-9 \mathrm{M}$ category).

Arguably, the contribution of BAB to broader balanced portfolio skew as opposed to UST market skew is the more relevant consideration for practitioners, particularly with balanced mandates, but the former results are nonetheless relevant to the original $\mathrm{BAB}_{\text {gov }}$ evidence. In any case, besides ex-post $\mathrm{BAB}_{\text {gov }}$ returns,

\footnotetext{
${ }^{46}$ Note that on average if longer-run Treasuries favorably contribute to portfolio coskew, they must have positive coskew when the market is skewed positively and negative coskew when the market is skewed negatively. Both scenarios command a premium-i.e., lower yields (higher prices) for duration—as Treasury duration reinforces benevolent positive skew in the first case but offsets undesirable negative skew in the second.

${ }^{47}$ The results and motivation from Barone-Adesi et al. (2004) might be analogous. They report coskew characteristics that command a positive (negative) risk premium and thereby account for abnormally high (low) small (large) cap stock returns, in perhaps the same way coskew might help account for $\mathrm{BAB}_{\text {gov }}$ excess returns.

48 This finding is also consistent with Chiang (2008), who uses monthly data from 1976 through 2005 on a broader set of U.S. fixed income sectors, including USTs, corporate bonds, and MBS.

${ }^{49}$ The negative conditional skew on BAB returns $(-0.09)$ is broadly consistent with "picking up nickels in front of steamrollers," whereas all points on the term structure are positively skewed. But, the Bowley coefficient is positive, and besides, coskew matters for asset pricing.
} 
another imperative is to evaluate the cost of hedging coskew risk ex-ante, similar to the covariance and PC exposures discussed previously. Table 7 reports the results from constrained optimizations from "low-risk government bond investing without coskew bets." These portfolios are long low-beta bonds as before, but subject to the constraint that the long and short sides have a weighted-average $\gamma$ of unity to match the market portfolio. The constraints follow both linear programming as well as non-linear optimization. The long side for the former constraint, given that $\gamma$ is additive like $\beta$ (Kraus and Litzenberger, 1976, pg. 1089), follows 50

$$
\begin{gathered}
\min _{\left\{w_{L}^{*}\right\}}\left[\left(w_{L, t}^{*}\right)^{T} \hat{\beta}_{t}\right] \\
\text { s.t. } \\
\left(w_{L, t}^{*}\right)^{T} \hat{\gamma}_{t}=n^{-1} \sum_{i=1}^{n} w_{i, t} \hat{\gamma}_{i, t}=1
\end{gathered}
$$

where $\hat{\gamma}_{t}$ is the vector of $\gamma$ estimates across the term structure, and $w_{i, t}$ is the market weight of the $i^{\text {th }}$ of $n$ duration buckets at time $t$. The long side for the latter optimization, with the same objective function and a non-linear equality constraint, follows

$$
\begin{gathered}
\min _{\left\{w_{L}^{*}\right\}}\left[\left(w_{L, t}^{*}\right)^{T} \hat{\beta}_{t}\right] \\
\text { s.t. } \\
\frac{\operatorname{cov}\left\{\left(w_{L, t}^{*}\right)^{T} r_{t}\left(r_{m, t}-\mu_{m, t}\right)^{2}\right\}}{E\left\{\left(r_{m, t}-\mu_{m, t}\right)^{3}\right\}}-1=0
\end{gathered}
$$

where $r_{t}$ is the $n \times 1$ vector of returns across the term structure, and $r_{m, t}$ is the corresponding market return with mean $\mu_{m, t} \cdot{ }^{51}$

${ }^{50}$ Correspondingly, the objective function and the linear constraint for the short side follow

$$
\begin{gathered}
\max _{\left\{w_{\mathrm{s}}^{*}\right\}}\left[\left(w_{\mathrm{S}, t}^{*}\right)^{T} \hat{\beta}_{t}\right] \\
\text { s.t. } \\
\left(w_{\mathrm{S}, t}^{*}\right)^{T} \hat{\gamma}_{t}=n^{-1} \sum_{i=1}^{n} w_{i, t} \hat{\gamma}_{i, t}
\end{gathered}
$$

${ }^{51}$ Similarly, the objective function and the linear constraint for the short side follow

$$
\begin{gathered}
\max _{\left\{w_{\mathrm{s}}^{*}\right\}}\left[\left(w_{\mathrm{S}, t}^{*}\right)^{T} \hat{\beta}_{t}\right] \\
\text { s.t. } \\
\operatorname{cov}\left\{\left(w_{\mathrm{S}, t}^{*}\right)^{T} r_{t}\left(r_{m, t}-\mu_{m, t}\right)^{2}\right\}\left[E\left\{\left(r_{m, t}-\mu_{m, t}\right)^{3}\right\}\right]^{-1}-1=0
\end{gathered}
$$


The results suggest a meaningful drag on excess returns, with an offsetting decline in volatility that still results in favorable SRs. As listed in Table 7, $\mathrm{BAB}_{\text {gov }}$ excess returns with non-linear (linear) gamma constraints with respect to the UST market is about 1.2 (1.7) bps per month, compared to 10.6 (4.0) bps per month for the unconstrained (standard) strategy. The SR is about 0.40 (0.58), compared to 1.27 (1.01) for the unconstrained portfolio (standard method). The results are similar given the balanced portfolio benchmark, and the costs of the ex-ante coskew hedge are evidenced by an excess return of 1.3 (1.6) bps per month under the nonlinear (linear) constraints, with a corresponding SR of about 0.40 (0.41). Returning to Tables 6 and 7, the results are broadly similar for the cross-section of government bond markets, although perhaps the reduction in excess returns and SRs are somewhat more pronounced compared to the corresponding unconstrained optimizations.

\section{Betting against gamma (BAG) and the market price of coskew risk}

These results on the third-moment risks of $\mathrm{BAB}_{\text {gov }}$ portfolios are somewhat ambiguous. On the one hand, some results suggest that $\mathrm{BAB}_{\text {gov }}$ excess returns (Frazzini and Pedersen, 2014) do compensate investors for coskew exposure, but on the other, Table 7 also suggests some residual excess returns to the strategy. Yet another natural and related empirical question is whether, similar to beta, investors can bet against gamma (BAG). Just as BAB is long "low risk," so is BAG, but with respect to the third as opposed to the as second moment. Instead of shorting high-beta assets, the trading strategy is to short assets with positive (negative) coskew, but only when unconditional market skew is negative (positive). The corresponding long side overweighs assets with negative (positive) coskew when market skew is unconditionally negative (positive).

To grasp intuition further, recall that under leverage constraints investors reach for yield and bid up prices of high-beta assets, more formally given that $\lambda_{\beta}>0$. By similar logic given the same leverage aversion, if skew preferences are also priced with $\lambda_{\gamma}<0$, then to earn further premiums and boost returns under constraints, investors might similarly overprice assets that have positive (negative) coskew with the market when the market is negatively (positively) skewed, all else equal. The long side of another trading strategy follows

$$
\begin{gathered}
\min _{\left\{w_{L}^{*}\right\}}\left[\left(w_{L, t}^{*}\right)^{T} \hat{\gamma}_{t}\right] \quad \text { if } M_{m, t}^{3}<0 \\
\max _{\left\{w_{L}^{*}\right\}}\left[\left(w_{L, t}^{*}\right)^{T} \hat{\gamma}_{t}\right] \text { if } M_{m, t}^{3}>0 \\
\text { s.t. } \\
\left(w_{L, t}^{*}\right)^{T} \hat{\beta}_{t}-1=0
\end{gathered}
$$


with the converse conditions for the short side, 52 and the return (given that both the long and short sides have market betas) is

$$
r_{t+1}^{B A G_{g v v}}=\left(r_{t+1}\right)^{T}\left(w_{L, t}^{*}-w_{S, t}^{*}\right)
$$

A similar approach closer to the canonical BAB tests follows

$$
r_{t+1}^{B A G_{g w}}= \begin{cases}\frac{1}{\left(w_{L}^{\gamma}\right)^{T} \hat{\beta}_{t}}\left[\left(w_{L}^{\gamma}\right)^{T} r_{t+1}-r^{f}\right]-\frac{1}{\left(w_{H}^{\gamma}\right)^{T} \hat{\beta}_{t}}\left[\left(w_{H}^{\gamma}\right)^{T} r_{t+1}-r^{f}\right] \quad \text { if } \quad M_{m, t}^{3}<0 \\ -\frac{1}{\left(w_{L}^{\gamma}\right)^{T} \hat{\beta}_{t}}\left[\left(w_{L}^{\gamma}\right)^{T} r_{t+1}-r^{f}\right]+\frac{1}{\left(w_{H}^{\gamma}\right)^{T} \hat{\beta}_{t}}\left[\left(w_{H}^{\gamma}\right)^{T} r_{t+1}-r^{f}\right] & \text { if } \quad M_{m, t}^{3}>0\end{cases}
$$

where analogous to (1), $w_{L(H)}^{\gamma}=k(z-\bar{z})^{-(+)}, k=2\left(1_{n}^{\prime}|z-\bar{z}|\right)^{-1}$, and $z=\operatorname{rank}\left(\hat{\gamma}_{i t}\right)$. Not unlike the linear constraints to the optimizations, the weights $\left[\left(w_{L(s)}^{\gamma}\right)^{T} \hat{\beta}_{t}\right]^{-1}$ on the long and short sides ensure that BAG gov portfolios have a market beta equal to one. ${ }^{53}$ Figure 4 shows the results based on (14) using the daily CRSP data, from June 1961 through December 2013, with a 3-year rolling window for estimation of covariance and coskew. Also, Figure 5 shows the corresponding results, but with respect to an alternative measure of coskew, $\beta_{S K D}$ from Harvey and Siddique (2000). Clearly, there is no evidence of excess returns to the strategy in either case, and none of the 10 other government bond markets produce meaningful excess returns to BAG.

Keep in mind, however, that the motivations for $\mathrm{BAG}_{\mathrm{gov}}$ as well as the hedges in the previous section assume preferences for positive portfolio skew. A remaining question is whether a three-moment CAPM, which clearly is not preference-free and instead requires that investors are risk-averse with non-increasing absolute risk aversion, in fact holds over the sample. That is, do investors indeed demand a negative (positive) premium for positive (negative) coskew when the UST market is positively (negatively) skewed? Toward that end, Figure 6 shows the covariance-coskew-excess return surface for eight maturity categories

52 That is, the objective and the linear constraint for the short side follow

$$
\begin{gathered}
\max _{\left\{w_{\mathrm{S}}^{*}\right\}}\left[\left(w_{\mathrm{S}, t}^{*}\right)^{T} \hat{\gamma}_{t}\right] \quad \text { if } M_{m, t}^{3}<0 \\
\min _{\left\{w_{\mathrm{s}}^{*}\right\}}\left[\left(w_{\mathrm{S}, t}^{*}\right)^{T} \hat{\gamma}_{t}\right] \quad \text { if } M_{m, t}^{3}>0 \\
\text { s.t. } \\
\left(w_{\mathrm{S}, t}^{*}\right)^{T} \hat{\beta}_{t}-1=0
\end{gathered}
$$

${ }^{53}$ Given that range of $\gamma$ across the term structure, unlike the distribution of (non-negative) $\beta$ s, straddles the origin, leveraging to a $\gamma$ of unity is not mathematically feasible. 
along the term structure, where $\beta$ and $\gamma$ are measured with respect to the UST portfolio using monthly data from June 1961 through December 2013. As expected and by visual inspection, the plane is positively sloped with respect to $\beta$, albeit perhaps moderately so, consistent with previous findings such as Black (1972). However, the slope vis-à-vis $\gamma \times \operatorname{sign}\left(M_{m}^{3}\right)$ is also positive, notably perversely so considering the positive unconditional skew of UST market returns over the full sample. Figure 7, which measures covariance and coskew with respect to the balanced portfolio and includes the $\beta_{S K D}$ measure (Harvey and Siddique, 2000) instead of $\gamma$, implies the same problematic inference. If investors prefer positive coskew, the surfaces in Figures 3 and 4 should be downward-sloping in $\gamma \times \operatorname{sign}\left(M_{m}^{3}\right)$ and $\beta_{S K D}$, respectively.

In addition to this informal evidence, simple asset-pricing tests based on regressions follow

$$
r_{i, t}^{e}=\alpha_{t}+\lambda_{\beta, t} \hat{\beta}_{i, t-s: t-1}+\lambda_{\gamma, t}\left[\hat{\gamma}_{i, t-s: t-1} \times \operatorname{sign}\left(M_{m, t-s: t-1}^{3}\right)\right]+\varepsilon_{i, t}
$$

with the Null hypotheses $\lambda_{\beta}>0$ and $\lambda_{\gamma}<0$, where $\hat{\beta}_{i}$ and $\hat{\gamma}_{i}$ for the $i^{\text {th }}$ asset as well as $M_{m}^{3}$, the unconditional standard market skew, are estimated from returns from $t-s$ to $t-1 .{ }^{54}$ Table 8 reports the results given the UST market as the benchmark index using alternative lag lengths of 12 and 36 months as well as a pure cross-sectional design with $\beta, \gamma$, and $\beta^{S K D}$ estimated over the complete sample period, with and without shrinkage of $\beta$ and $\gamma$, and given both daily and monthly return data. Similarly, Table 9 shows the results that correspond to the balanced portfolio of USTs and stocks as alternative benchmarks. Given the small Fama-Macbeth (1973) t statistics on $\lambda_{\gamma}$ in each case, as well as some perverse positive coefficient estimates, the clear inference is that coskew does not, after all, seem to be priced following the standard threemoment CAPM. Then again, the $\beta$ estimates, which have the expected positive sign more consistently, are nevertheless not statistically significant, either. These ambiguous results, which are not dissimilar to previous findings for a broader cross-section of bonds (Chiang, 2008) but inconsistent with the general evidence that $\lambda_{\gamma}<0$ from Kraus and Litzenberger (1976) and Friend and Westerfield (1980), 55 raise some questions about the motivations for BAG and hedging coskew risks. At the same time, they do not necessarily comprise

\footnotetext{
54 The alternative in the lower panels of Tables 9 and 10 follow Harvey and Siddique (2000), as in $r_{i, t}^{e}=\alpha_{t}+\lambda_{\beta, t} \hat{\beta}_{i, \mathrm{t}-s: t-1}+\lambda_{\gamma, t} \hat{\beta}_{i, t-s: t-1}^{S K D}+\varepsilon_{i, t}$

${ }^{55}$ Friend and Westerfield (1980), however, question the broader inference in Kraus and Litzenberger (1976) that the addition of coskew preferences largely accounts for previous violations of the two-moment CAPM, including that the implied risk-free rate is distinguishable from the actual risk-free rate.
} 
corroboration of, say, Taleb's (2004) alternative view that investors prefer negative coskew, which draws from the effects of small samples of observed returns, ${ }^{56}$ prospect theory (PT),${ }^{57}$ or hedonic psychology. .58

\section{Summary}

As Frazzini and Pedersen (2014) as well as Asness et al. $(2012,2014)$ and others note, the magnitude of $\mathrm{BAB}$ excess returns, notably including published returns for $\mathrm{BAB}_{\mathrm{gov}}$ in particular, are perhaps as compelling as for any other apparent violation of asset pricing theory such as size, value, or momentum.

Given motivations for investors and central bankers alike to understand the price and quantity of risk along the term structure, the preceding analyses devotes exclusive attention to $\mathrm{BAB}_{\text {gov }}$ with respect to simple outof-sample tests, further consideration of covariance with risky assets, a broader specification of the underlying asset pricing model more consistent with GATSMs as opposed to the single-factor CAPM, and coskew with respect to both the risk-free, relevant to $\mathrm{BAB}$, and risky asset classes, germane to RP.

On balance, the results are somewhat mixed. $\mathrm{BAB}_{\text {gov }}$ returns do appear to have diminished somewhat in recent decades, especially during the last five years. This trend in turn might owe to the postcrises experience with the zero lower bound for nominal interest rates and unconventional policy measures, to the extent that central bankers have pinned down short rates and decreased their near-term sensitivity to macroeconomic news, or given the "portfolio-rebalancing" channel in which large scale asset purchases (persistently) push down longer-dated UST yields. ${ }^{59}$ In addition, some evidence also suggests that the phenomenon might be largely confined to USTs, which may question the universal application of leverage aversion theory behind $\mathrm{BAB}$ or highlight the possibly unique role for USTs as a global safe-haven asset. Even so, $\mathrm{BAB}_{\text {gov }}$ returns do not appear to compensate investors for special FTQ-related demand for USTs at the back as opposed to the front end of the term structure. Instead, alternative $\mathrm{BAB}_{\text {gov }}$ trading strategies with simple linear programming constraints to hedge covariance with stock returns tend to produce not only nearly as favorable risk-adjusted results but also comparable absolute excess returns.

If anything, more evidence suggests that $\mathrm{BAB}_{\text {gov }}$ compensates investors for coskew rather than covariance risks, but lucid conclusions are hard to draw. Some results suggest that ex-post $\mathrm{BAB}_{\text {gov }}$ excess

\footnotetext{
${ }^{56}$ Skew exacerbates the "small numbers" effect, because the observed mean (variance) will differ from (be lower than) the observed mean (variance).

${ }^{57}$ The value function of PT implies decreased sensitivity to both gains and losses and therefore an overall preference for negative skew. Agents under PT are more concerned with changes than with accumulated wealth, as the value function is concave (convex) in the profit (loss) domain (and the value of a large loss is greater than the corresponding sum of losses).

58 The central notion in hedonic psychology is that agents soon revert to a "set-point of utility" after some shock, as again changes in utility rather than absolute (cumulative) levels affect preferences, and similar to PT, the implied value function is concave (convex) in the profit (loss) domain.

${ }^{59}$ The Federal Reserve's maturity extension program announced on September 21, 2011—otherwise and informally known as an "operation twist two"- - might also affect $\mathrm{BAB}_{\text {gov }}$ returns by depressing expected returns at the back end of the term structure, all else equal.
} 
returns reflect a negative premium for coskew, but curiously perhaps with respect to the UST market (e.g., Frazzini and Pedersen, 2014) as opposed to a broader portfolio of bonds and shares. Ex-ante hedges to neutralize coskew risks with respect to either market proxy, unlike the results for covariance, appear to be costly in terms of foregone excess returns. But to muddy the waters further, standard asset pricing tests do not seem to support the three-moment CAPM for these data, and therefore such hedges may be unwarranted if investors in fact have neither positive (Kraus and Litzenberger, 1976) or negative portfolio skew preferences (Taleb, 2004). In addition, $B A G_{\text {gov }}$ does not seem to produce excess returns, hedged for underlying beta exposure. Whatever these results, "low-risk" investing refers to second- rather than thirdmoment risks, and further analyses of $\mathrm{BAB}$ should arguably test for coskew preferences routinely.

The previous discussion does not fully address managerial delegation and benchmarking as another explanation for $\mathrm{BAB}_{\text {gov }}$ returns, following Baker et al. (2012). Indeed, returning to Table 2, the information ratios (IRs) (0.19) for even the most profitable strategies are unremarkable, which might help explain why a meaningful number of institutional investors do not exploit these favorable patterns. However, a low IR is neither a necessary nor sufficient condition to explain favorable absolute-risk-adjusted returns. Perhaps the most problematic result for $\mathrm{BAB}_{\text {gov }}$ is that, although the ex-post loadings appear favorable, as they do for term structure momentum (Durham, 2013b), the ex-ante hedges for level, slope, and curvature exposure largely erase the gains from the strategy, using both the CRSP data on USTs and the Bloomberg data on the broader cross-section. Again, as argued previously, the fact that GATSM parameters may readily reproduce an inverse schedule between SRs and maturity does not imply abnormal $\mathrm{BAB}_{\text {gov }}$ returns, but rather to the contrary that such an empirical relation is not necessarily inconsistent with the no-arbitrage condition. 


\section{References}

Adrian, Tobias, Richard Crump, and Emanuel Moench, 2013, "Pricing the Term Structure with Linear Regressions," Journal of Financial Economics, vol. 110, pp. 110-138.

Adrian, Tobias, Erkko Etula, and Tyler Muir, 2014, "Financial Intermediaries and the Cross-Section of Asset Returns," Journal of Finance, vol. 69, no. 6, pp. 2557-96.

Asness, Clifford, Andrea Frazzini, and Lasse H. Pedersen, 2014, "Low-Risk Investing without Industry Bets," Financial Analysts Journal, vol. 70, no. 4, pp. 24-41.

Asness, Clifford, Andrea Frazzini, and Lasse H. Pedersen, 2012, "Leverage Aversion and Risk Parity," Financial Analysts Journal, vol. 68, no. 1, pp. 47-59.

Baker, Malcom, Brendan Bradly, and Jeffrey Wurgler, 2011, "Benchmarks as Limits to Arbitrage: Understanding the Low-Volatility Anomaly,” Financial Analysts Journal, vol. 67, no. 1, pp. 40-54.

Barone Adesi, Giovanni, Patrick Gagliardini, and Giovanni Urga, 2004, "Testing Asset Pricing Models with Coskewness," Journal of Business and Economic Statistics, vol. 22, no. 4, pp. 474-485.

Baz, Jamil, and George Chacko, 2004, Financial Derivatives: Pricing, Applications, and Mathematics, Cambridge University Press.

Bernanke, Ben, 2010, “The Economic Outlook and Monetary Policy, speech at Jackson Hole, Wyoming. Black, Fischer, 1972, “Capital Market Equilibrium with Restricted Borrowing," Journal of Business, vol. 45, no. 3, pp. 444-455.

Black, Fischer, Michael C. Jensen, and Myron S. Scholes, 1972, “The Capital Asset Pricing Model: Some Empirical Tests," In Studies in the Theory of Capital Markets. Edited by Michael C. Jensen. New York: Praeger.

Campbell, John Y. and Luis M. Viceira, 2001, "Who Should Buy Long Term Bonds," American Economic Review, vol. 91, no. 1, pp. 99-127.

Chow, Tzee-man, Jason C. Hsu, Li-Lan Kuo, and Feifei Li, 2014, "A Study of Low-Volatility Portfolio Construction Methods," Journal of Portfolio Management, vol. 40, no. 4, pp. 89-105.

Chiang, I-Hsuan Ethan, 2008, "Skewness and Co-skewness in Bond Returns," working paper, Boston College.

Diether, Karl B., Christopher J. Malloy, and Anna Scherbina, 2002, "Differences of Opinion and the Cross Section of Stocks Returns," Journal of Finance, vol. 57. no. 5, pp. 2133-2141.

Duarte, Jefferson, Francis Longstaff, and Fan Yu, 2007, "Risk and Return in Fixed-Income Arbitrage: Nickels in Front of a Steamroller?” Review of Financial Studies, vol. 20, no. 3, pp. 769-811.

Duffee, Gregory R., 2010, “Sharpe Ratios in Term Structure Models,” working paper.

Durham, J. Benson, 2008, "Implied Interest Rate Skew, Term Premiums, and the 'Conundrum," Journal of Fixed Income, vol. 17, no. 4, pp. 88-99. 
Durham, J. Benson, 2013a, “Arbitrage-Free Models of Stocks and Bonds," Federal Reserve Bank of New York Staff Reports, no. 656.

Durham, J. Benson, 2013b, "Momentum and the Term Structure of Interest Rates," Federal Reserve Bank of New York Staff Reports, no. 657.

Gürkaynak, Refet S., Brian P. Sack, and Eric T. Swanson, 2005, "The Sensitivity of Long-Term Interest Rates to Economic News: Evidence and Implications for Macroeconomic Models," American Economic Review, vol. 95, no. 1, pp. 425-436.

Gürkaynak, Refet S., Brian P. Sack, and Jonathan Wright, 2007, “The U.S. Treasury Yield Curve: 1961 to the Present," Journal of Monetary Economics, vol. 54, no. pp. 2291-2304.

Fama, Eugene F. and Kenneth R. French, 1993, "Common Risk Factors in the Returns on Stocks and Bonds," Journal of Financial Economics, vol. 33, pp. 3-56.

Fama, Eugene F. and James D. MacBeth, 1973, “Risk, Return, and Equilibrium: Empirical Tests," Journal of Political Economy, vol. 81, no. 3, pp. 607-636.

Frazzini, Andrea and Lasse Heje Pedersen, 2014, “Betting Against Beta," Journal of Financial Economics, vol. 111, pp. 1-25.

Friend, Irwin and Randolph Westerfield, 1980, "Co-Skewness and Capital Asset Pricing," Journal of Finance, vol. 35, no. 4, pp. 897-913.

Fujiwara, Ippei, Lena Mareen Korber, and Daisuke Nagakura, 2013, “Asymmetry in Government Bond Returns," Journal of Banking and Finance, vol. 37, pp. 3218-3226.

Harvey, Campbell and Akhtar Siddique, 2000, "Conditional Skewness in Asset Pricing Tests," Journal of Finance, vol. 55, no. 3, pp. 1263-1295.

Hong, Harrison and David Sraer, 2012, "Speculative Betas," working paper.

Kraus, Alan and Robert H. Litzenberger, 1976, "Skewness Preference and the Valuation of Risk Assets," Journal of Finance, vol. 31, no. 4, pp. 1085-1100.

Li, Canlin and Min Wei, 2012, “Term Structure Modelling with Supply Factors and the Federal Reserve's Large Scale Asset Purchase Programs,” Finance and Economics Discussion Series, no. 2012-37, Federal Reserve Board.

Langetieg, Terence C., 1980, “A Multivariate Model of the Term Structure,” Journal of Finance, vol. 35, no. 1, pp. 71-97.

Miller, Edward M., 1977, "Risk, Uncertainty, and Divergence of Opinion,” Journal of Finance, vol. 32, pp. $1151-1168$.

Mitton, Todd and Keith Vorkink, 2007, "Equilibrium Underdiversification and the Preference for Skewness," Review of Financial Studies, vol. 20, no. 4, pp. 1255-1288. 
Roll, Richard, 1977, “A Critique of the Asset Pricing Theory's Tests Part I: On Past and Potential Testability of the Theory", Journal of Financial Economics, vol. 4, no. 2, pp. 129-76.

Taleb, Nassim, 2004, "Bleed or Blowup? Why Do We Prefer Asymmetric Payoffs?” Journal of Behavioral Finance, no. 5, no. 1, pp. 2-7.

Walkshäusl, Christian, 2014, “International Low-Risk Investing," Journal of Portfolio Management, vol. 41, no. 1, pp. 45-56. 
Table 1

Betting Against Beta (BAB) Results

U.S. Treasury Market: CRSP Data

Return Frequency

Lags (Months)

Beta Shrinkage based on Vasicek (1973)?

Sample Begin

Sample End

Observations

Gov. Bond Market Excess Return

Gov. Bond Market Sharpe Ratio

Gov. Bond \& Equity Market Excess Return

Gov. Bond \& Equity Market Sharpe Ratio

Equity Market Excess Return

Equity Market Sharpe Ratio

Mean Beta Long Side (BAB)

Mean Beta Short Side (BAB)

BAB Excess Return

BAB Sharpe Ratio

Ex Post BAB Alpha (UST)

Ex Post BAB Beta (UST)

\begin{tabular}{ccc|c|cccc}
\cline { 3 - 5 } Daily & Daily & Daily & Daily & Monthly & Monthly & Monthly & Monthly \\
11 & 35 & 11 & 35 & 11 & 59 & 11 & 59 \\
No & No & Yes & Yes & No & No & Yes & Yes
\end{tabular}

31-May-1962 28-May-1964 31-May-1962 28-May-1964 31-May-1962 31-May-1966 31-May-1962 31-May-1966

31-Dec-2013 31-Dec-2013 31-Dec-2013 31-Dec-2013 31-Dec-2013 31-Dec-2013 31-Dec-2013 31-Dec-2013

\begin{tabular}{ccc|c|cccc}
620 & 596 & 620 & 596 & 616 & 568 & 616 & 568 \\
$0.012 \%$ & $0.027 \%$ & $0.012 \%$ & $0.027 \%$ & $0.126 \%$ & $0.544 \%$ & $0.126 \%$ & $0.544 \%$ \\
0.22882 & 0.47461 & 0.22882 & 0.47461 & 0.11267 & 0.47246 & 0.11267 & 0.47246 \\
$0.022 \%$ & $0.036 \%$ & $0.022 \%$ & $0.036 \%$ & $0.391 \%$ & $0.804 \%$ & $0.391 \%$ & $0.804 \%$ \\
0.12668 & 0.20757 & 0.12668 & 0.20757 & 0.10838 & 0.21929 & 0.10838 & 0.21929 \\
$0.026 \%$ & $0.040 \%$ & $0.026 \%$ & $0.040 \%$ & $0.512 \%$ & $0.906 \%$ & $0.512 \%$ & $0.906 \%$ \\
0.12249 & 0.18609 & 0.12249 & 0.18609 & 0.1133 & 0.19756 & 0.1133 & 0.19756 \\
& & & & & & & \\
0.36939 & 0.37999 & 0.47706 & 0.42569 & 0.38969 & 0.4039 & 0.41993 & 0.4251 \\
2.0451 & 2.0115 & 1.8085 & 1.856 & 1.9935 & 1.9336 & 1.7574 & 1.8289 \\
$0.020 \%$ & $0.048 \%$ & $0.012 \%$ & $0.040 \%$ & $0.147 \%$ & $0.861 \%$ & $0.110 \%$ & $0.782 \%$ \\
0.5698 & 1.1353 & 0.36728 & 1.0089 & 0.21167 & 1.0782 & 0.16216 & 0.97663 \\
0.00017742 & 0.00042715 & 0.0001433 & 0.00039173 & 0.0014908 & 0.0085981 & 0.0012693 & 0.0083594 \\
0.12761 & 0.14589 & -0.24491 & -0.039562 & 0.020265 & -0.039315 & -0.16145 & -0.1437
\end{tabular}


Table 2

U.S. Treasury Market (CRSP Data) (Daily)

28-May-1964--31-Dec-2013

Lag Length for Rolling Beta Estimation: (36)

Note: Beta Shrinkage follows Vasicek (1973)

\begin{tabular}{|c|c|c|c|c|c|c|c|c|c|c|c|c|}
\hline Maturity Buckets: & $1 \mathrm{M}-9 \mathrm{M}$ & $9 \mathrm{M}-2 \mathrm{Y}$ & $2 Y-3 Y$ & $3 Y-4 Y$ & $4 Y-5 Y$ & $5 Y-6.5 Y$ & $6.5 \mathrm{Y}-12 \mathrm{Y}$ & $12 \mathrm{Y}+$ & $\mathrm{BAB}$ & $\begin{array}{c}\text { Gov. } \\
\text { Bond } \\
\text { Market } \\
\text { Portfolio }\end{array}$ & $\begin{array}{l}\text { Bond \& } \\
\text { Equity } \\
\text { Market } \\
\text { Portfolio }\end{array}$ & $\begin{array}{c}\text { Stodk } \\
\text { Market }\end{array}$ \\
\hline Mean Duration (years) & 0.42 & 1.31 & 2.32 & 3.14 & 3.94 & 4.81 & 6.47 & 11.86 & 0.00 & 4.28 & $\mathrm{~N} / \mathrm{A}$ & $\mathrm{N} / \mathrm{A}$ \\
\hline Mean Excess Return & $0.023 \%$ & $0.025 \%$ & $0.026 \%$ & $0.027 \%$ & $0.028 \%$ & $0.029 \%$ & $0.030 \%$ & $0.031 \%$ & $0.040 \%$ & $0.027 \%$ & $0.036 \%$ & $0.040 \%$ \\
\hline Mean Std. Dev. & 0.00017 & 0.00032 & 0.00049 & 0.00061 & 0.00072 & 0.00084 & 0.00101 & 0.00143 & 0.00040 & 0.00056 & 0.00173 & 0.00214 \\
\hline Mean Sharpe Ratio & 1.35880 & 0.77795 & 0.53289 & 0.44859 & 0.38437 & 0.34677 & 0.29452 & 0.21384 & 1.00890 & 0.47461 & 0.20757 & 0.18609 \\
\hline Mean Information Ratio & -0.08193 & -0.05842 & -0.01376 & 0.04761 & 0.05710 & 0.07969 & 0.06476 & 0.04288 & 0.19210 & 0.00000 & $\mathrm{~N} / \mathrm{A}$ & $\mathrm{N} / \mathrm{A}$ \\
\hline Mean Ex ante Alpha w.r.t. Gov. Bonds & 0.00018 & 0.00014 & 0.00006 & 0.00000 & -0.00006 & -0.00009 & -0.00018 & -0.00033 & $\mathrm{~N} / \mathrm{A}$ & 0.00000 & $\mathrm{~N} / \mathrm{A}$ & $\mathrm{N} / \mathrm{A}$ \\
\hline Ex post Alpha w.r.t. Gov. Bonds & 0.00017 & 0.00010 & 0.00003 & 0.00000 & -0.00006 & -0.00010 & -0.00016 & -0.00029 & 0.00039 & 0.00000 & $\mathrm{~N} / \mathrm{A}$ & $\mathrm{N} / \mathrm{A}$ \\
\hline Ex post Alpha w.r.t. Gov. Bonds \& Equities & 0.00021 & 0.00021 & 0.00020 & 0.00019 & 0.00019 & 0.00020 & 0.00020 & 0.00018 & 0.00038 & 0.00021 & $\mathrm{~N} / \mathrm{A}$ & $\mathrm{N} / \mathrm{A}$ \\
\hline Ex post Alpha w.r.t. Equities & 0.00022 & 0.00021 & 0.00021 & 0.00021 & 0.00021 & 0.00022 & 0.00021 & 0.00020 & 0.00038 & 0.00022 & $\mathrm{~N} / \mathrm{A}$ & $\mathrm{N} / \mathrm{A}$ \\
\hline Ex post Alpha w.r.t. L & 0.00022 & 0.00024 & 0.00025 & 0.00027 & 0.00027 & 0.00028 & 0.00029 & 0.00030 & 0.00039 & $\mathrm{~N} / \mathrm{A}$ & $\mathrm{N} / \mathrm{A}$ & $\mathrm{N} / \mathrm{A}$ \\
\hline Ex post Alpha w.r.t. L-S & 0.00022 & 0.00024 & 0.00025 & 0.00026 & 0.00027 & 0.00028 & 0.00029 & 0.00030 & 0.00039 & $\mathrm{~N} / \mathrm{A}$ & $\mathrm{N} / \mathrm{A}$ & $\mathrm{N} / \mathrm{A}$ \\
\hline Ex post Alpha w.r.t. L-S-C & 0.00022 & 0.00024 & 0.00025 & 0.00026 & 0.00027 & 0.00028 & 0.00029 & 0.00030 & 0.00039 & $\mathrm{~N} / \mathrm{A}$ & $\mathrm{N} / \mathrm{A}$ & $\mathrm{N} / \mathrm{A}$ \\
\hline Mean Ex ante Beta w.r.t. Gov. Bonds & 0.22787 & 0.40944 & 0.75780 & 1.00400 & 1.20460 & 1.42420 & 1.75720 & 2.18490 & 0.00000 & 1.00000 & $\mathrm{~N} / \mathrm{A}$ & $\mathrm{N} / \mathrm{A}$ \\
\hline Ex post Beta w.r.t. Gov. Bonds & 0.17451 & 0.48740 & 0.81803 & 1.04440 & 1.25740 & 1.46460 & 1.75600 & 2.32920 & -0.03956 & 1.00000 & $\mathrm{~N} / \mathrm{A}$ & $\mathrm{N} / \mathrm{A}$ \\
\hline Ex post Beta w.r.t. Gov. Bonds \& Equities & 0.00885 & 0.02894 & 0.04670 & 0.05445 & 0.06240 & 0.07347 & 0.10554 & 0.13232 & -0.00541 & 0.04976 & $\mathrm{~N} / \mathrm{A}$ & $\mathrm{N} / \mathrm{A}$ \\
\hline Ex post Beta w.r.t. Equities & 0.00412 & 0.01557 & 0.02511 & 0.02835 & 0.03185 & 0.03767 & 0.05898 & 0.07137 & -0.00406 & 0.02515 & $\mathrm{~N} / \mathrm{A}$ & $\mathrm{N} / \mathrm{A}$ \\
\hline Ex post Beta w.r.t. Level & 0.00001 & 0.00001 & 0.00001 & 0.00001 & 0.00001 & 0.00001 & 0.00001 & 0.00001 & 0.00002 & $\mathrm{~N} / \mathrm{A}$ & $\mathrm{N} / \mathrm{A}$ & $\mathrm{N} / \mathrm{A}$ \\
\hline Ex post Beta w.r.t. Slope & -0.00002 & 0.00000 & 0.00001 & 0.00003 & 0.00004 & 0.00005 & 0.00006 & 0.00007 & -0.00004 & $\mathrm{~N} / \mathrm{A}$ & $\mathrm{N} / \mathrm{A}$ & $\mathrm{N} / \mathrm{A}$ \\
\hline Ex post Beta w.r.t. Curvature & 0.00002 & -0.00002 & -0.00004 & -0.00005 & -0.00005 & -0.00003 & -0.00003 & -0.00003 & -0.00003 & $\mathrm{~N} / \mathrm{A}$ & $\mathrm{N} / \mathrm{A}$ & $\mathrm{N} / \mathrm{A}$ \\
\hline Mean Ex ante Gamma w.r.t. Gov. Bonds & 0.86568 & 1.16570 & 1.25380 & 0.90928 & 0.81397 & 0.97542 & 0.90623 & 1.48950 & $\mathrm{~N} / \mathrm{A}$ & 1.00000 & 1.00000 & $\mathrm{~N} / \mathrm{A}$ \\
\hline Ex post Gamma w.r.t. Gov. Bonds & 0.50028 & 0.86677 & 1.12880 & 1.13530 & 1.32450 & 1.43060 & 1.58330 & 1.85590 & 0.44033 & 1.00000 & 1.00000 & $\mathrm{~N} / \mathrm{A}$ \\
\hline Ex post Gamma w.r.t. Gov. Bonds \& Equities & -0.01356 & -0.04403 & -0.07603 & -0.10181 & -0.09788 & -0.08920 & -0.05871 & -0.06583 & -0.05717 & -0.05301 & 1.00000 & $\mathrm{~N} / \mathrm{A}$ \\
\hline Ex post Gamma w.r.t. Equities & -0.01169 & -0.03559 & -0.06051 & -0.08252 & -0.08060 & -0.07750 & -0.05985 & -0.07827 & -0.04435 & -0.04860 & 1.00000 & $\mathrm{~N} / \mathrm{A}$ \\
\hline Mean Unconditional Skewness & 2.00500 & 1.92350 & 1.19940 & 0.60563 & 0.53735 & 0.41483 & 0.39851 & 0.27563 & -0.09448 & 0.53631 & -0.97335 & -0.96641 \\
\hline Mean Unconditional Bowley Skewness & 0.00311 & 0.19692 & 0.11187 & 0.09314 & 0.12808 & 0.06841 & 0.06587 & 0.08610 & 0.03139 & 0.09322 & -0.06855 & -0.08772 \\
\hline
\end{tabular}


Table 3

Betting Against Beta (BAB) Results: 11 Government Bond Markets: Bloomberg and MSCI Data

Return Frequency

Lags (Months)

Beta Shrinkage based on Vasicek (1973)?

Sample Begin

Sample End

Observations

Gov. Bond Market Excess Return

Gov. Bond Market Sharpe Ratio

Gov. Bond \& Equity Market Excess Return

Gov. Bond \& Equity Market Sharpe Ratio

Equity Market Excess Return

Equity Market Sharpe Ratio

Mean Beta Long Side (BAB)

Mean Beta Short Side (BAB)

BAB Excess Return

BAB Sharpe Ratio

Ex Post BAB Alpha (UST)

Ex Post BAB Beta (UST)

\begin{tabular}{|c|c|c|c|c|c|c|c|c|c|c|}
\hline Germany & France & Netherlands & Belgium & Italy & Spain & Japan & UK & Canada & Switzerland & US \\
\hline Monthly & Monthly & Monthly & Monthly & Monthly & Monthly & Monthly & Monthly & Monthly & Monthly & Monthly \\
\hline Yes & Yes & Yes & Yes & Yes & Yes & Yes & Yes & Yes & Yes & Yes \\
\hline $11 / 2014$ & $11 / 2014$ & $11 / 2014$ & $11 / 2014$ & $11 / 2014$ & $11 / 2014$ & $11 / 2014$ & $11 / 2014$ & $11 / 2014$ & $11 / 2014$ & $11 / 2014$ \\
\hline 239 & 236 & 222 & 144 & 176 & 156 & 212 & 239 & 239 & 173 & 239 \\
\hline $0.325 \%$ & $0.350 \%$ & $0.356 \%$ & $0.330 \%$ & $0.292 \%$ & $0.289 \%$ & $0.202 \%$ & $0.272 \%$ & $0.338 \%$ & $0.240 \%$ & $0.299 \%$ \\
\hline 0.12798 & 0.14582 & 0.15111 & 0.086355 & 0.004269 & 0.088641 & 0.061113 & 0.13288 & 0.18394 & 0.10835 & 0.19686 \\
\hline $0.458 \%$ & $0.429 \%$ & $0.514 \%$ & $0.266 \%$ & $-0.265 \%$ & $0.315 \%$ & $0.111 \%$ & $0.285 \%$ & $0.541 \%$ & $0.271 \%$ & $0.575 \%$ \\
\hline 0.072661 & 0.080558 & 0.089568 & 0.038657 & -0.046158 & 0.051551 & 0.021137 & 0.071149 & 0.11895 & 0.057728 & 0.12915 \\
\hline 0.06352 & 0.065748 & 0.059972 & 0.073706 & 0.094568 & 0.09057 & 0.030737 & 0.067853 & 0.08775 & 0.070315 & 0.062666 \\
\hline-0.10146 & -0.023375 & -0.11011 & 0.26753 & 0.074167 & 0.10345 & 0.19986 & -0.066585 & -0.10072 & -0.084222 & -0.19893 \\
\hline
\end{tabular}


Table 4

\title{
BAB Unconstrained and Contrained Strategies: Covariance \& PCs U.S. Treasury Market: CRSP Data
}

\author{
Return Frequency \\ Lags (Months) \\ Beta Shrinkage based on Vasicek (1973)? \\ Sample Begin \\ Sample End \\ Observations \\ Stock Market Sharpe Ratio \\ Gov. Bond Market Sharpe Ratio \\ BAB [F\&P 2014] Sharpe Ratio \\ Unconstrained \\ Mean Beta Long Side \\ Mean Beta Short Side \\ Excess Return \\ Sharpe Ratio \\ Equity Beta Inequality Constraint (Gov. Bonds \& Equities) \\ Mean Beta Long Side \\ Mean Beta Short Side \\ Excess Return \\ Sharpe Ratio \\ Equity Beta Inequality Constraint (Equities) \\ Mean Beta Long Side \\ Mean Beta Short Side \\ Excess Return \\ Sharpe Ratio \\ Slope Beta Equality Constraint \\ Mean Beta Long Side \\ Mean Beta Short Side \\ Excess Return \\ Sharpe Ratio \\ Slope-Curvature Beta Equality Constraint \\ Mean Beta Long Side \\ Mean Beta Short Side \\ Excess Return \\ Sharpe Ratio \\ Level-Slope-Curvature Beta Equality Constraint \\ Mean Beta Long Side \\ Mean Beta Short Side \\ Excess Return \\ Sharpe Ratio
}

\begin{tabular}{|c|c|c|c|}
\hline Daily & Daily & Monthly & Monthly \\
\hline 11 & 35 & 11 & 59 \\
\hline Yes & Yes & Yes & Yes \\
\hline $05 / 1962$ & $05 / 1964$ & $05 / 1962$ & $05 / 1966$ \\
\hline $12 / 2013$ & $12 / 2013$ & $12 / 2013$ & $12 / 2013$ \\
\hline 620 & 596 & 616 & 568 \\
\hline 0.12249 & 0.18609 & 0.1133 & 0.19756 \\
\hline 0.12668 & 0.20757 & 0.10838 & 0.21929 \\
\hline 0.36728 & 1.0089 & 0.16216 & 0.97663 \\
\hline 0.32666 & 0.20096 & 0.15243 & 0.15495 \\
\hline 2.1679 & 2.221 & 2.0624 & 2.1652 \\
\hline $0.018 \%$ & $0.106 \%$ & $0.504 \%$ & $2.938 \%$ \\
\hline 0.31779 & 1.2702 & 0.2833 & 1.2629 \\
\hline 0.7089 & 0.58412 & 0.50434 & 0.49487 \\
\hline 2.1679 & 2.221 & 2.0624 & 2.1652 \\
\hline $0.018 \%$ & $0.101 \%$ & $0.357 \%$ & $2.374 \%$ \\
\hline 0.38889 & 1.2224 & 0.27363 & 1.1763 \\
\hline 0.82717 & 0.67268 & 0.6961 & 0.56458 \\
\hline 2.1679 & 2.221 & 2.0624 & 2.1652 \\
\hline $0.016 \%$ & $0.088 \%$ & $0.286 \%$ & $2.323 \%$ \\
\hline 0.35359 & 1.0917 & 0.25625 & 1.1529 \\
\hline 0.71046 & 0.73884 & 0.61251 & 0.66382 \\
\hline 1.4282 & 1.3112 & 1.4111 & 1.3752 \\
\hline $0.006 \%$ & $0.014 \%$ & $0.049 \%$ & $0.467 \%$ \\
\hline 0.23055 & 0.42956 & 0.07557 & 0.54684 \\
\hline 0.8625 & 0.87564 & 0.81768 & 0.84688 \\
\hline 1.1596 & 1.0947 & 1.1009 & 1.1319 \\
\hline $0.005 \%$ & $0.004 \%$ & $0.101 \%$ & $0.142 \%$ \\
\hline 0.28829 & 0.22594 & 0.057628 & 0.36354 \\
\hline 0.90727 & 0.92986 & 0.89964 & 0.93943 \\
\hline 1.0721 & 1.0299 & 1.0079 & 1.0334 \\
\hline $0.002 \%$ & $0.002 \%$ & $0.011 \%$ & $0.038 \%$ \\
\hline 0.22835 & 0.2114 & 0.058671 & 0.17551 \\
\hline
\end{tabular}


Table $5^{60}$

BAB Trading Strategies: 11 Government Bond Markets: Bloomberg and MSCI Data

Lag Length (Months): (36)

Note: Beta Shrinkage follows Vasicek (1973)

Excess Returns

\begin{tabular}{|c|c|c|c|c|c|c|c|c|c|c|c|c|c|c|c|c|}
\hline $\begin{array}{l}\text { Constraint: } \\
\text { Non-Linear? }\end{array}$ & & & & & $\begin{array}{l}\text { None } \\
\text { N/A }\end{array}$ & $\begin{array}{l}\text { Equ. } \\
\text { No }\end{array}$ & $\begin{array}{l}\text { Equ. } \\
\text { No }\end{array}$ & $\begin{array}{c}\text { S } \\
\text { No }\end{array}$ & $\begin{array}{l}\text { S-C } \\
\text { No }\end{array}$ & $\begin{array}{l}\text { L-S-C } \\
\text { No }\end{array}$ & $\begin{array}{c}\text { Gamma } \\
\text { No }\end{array}$ & $\begin{array}{c}\text { Gamma } \\
\text { Yes }\end{array}$ & $\begin{array}{c}\text { Beta_SKD } \\
\text { No }\end{array}$ & $\begin{array}{l}\text { Gamma } \\
\text { No }\end{array}$ & $\begin{array}{c}\text { Gamma } \\
\text { Yes }\end{array}$ & $\begin{array}{c}\text { Beta_SKD } \\
\text { No }\end{array}$ \\
\hline Beta w.r.t. (Market) & Gov. & Gov.\&Equ & Equ. & $\mathrm{BAB}$ (F\&P) & Gov. & Gov.\&Equ & Equ. & Gov. & Gov. & Gov. & Gov. & Gov. & Gov & Gov.\&Equ & Gov.\&Equ & Gov.\&Equ. \\
\hline Germany & $0.322 \%$ & $0.386 \%$ & $0.450 \%$ & $0.337 \%$ & $1.373 \%$ & $1.204 \%$ & $0.374 \%$ & $-0.031 \%$ & $-0.048 \%$ & $-0.030 \%$ & $-0.010 \%$ & $0.139 \%$ & $0.500 \%$ & $0.266 \%$ & $0.334 \%$ & $0.342 \%$ \\
\hline France & $0.347 \%$ & $0.387 \%$ & $0.428 \%$ & $0.425 \%$ & $2.124 \%$ & $2.098 \%$ & $0.755 \%$ & $0.106 \%$ & $-0.004 \%$ & $0.003 \%$ & $0.184 \%$ & $0.301 \%$ & $0.227 \%$ & $0.142 \%$ & $0.146 \%$ & $0.616 \%$ \\
\hline Netherlands & $0.354 \%$ & $0.430 \%$ & $0.506 \%$ & $0.418 \%$ & $1.327 \%$ & $1.279 \%$ & $0.780 \%$ & $0.039 \%$ & $-0.029 \%$ & $-0.024 \%$ & $-0.021 \%$ & $0.138 \%$ & $0.225 \%$ & $0.075 \%$ & $0.347 \%$ & $0.394 \%$ \\
\hline Belgium & $0.324 \%$ & $0.293 \%$ & $0.261 \%$ & $0.360 \%$ & $1.977 \%$ & $1.916 \%$ & $0.153 \%$ & $0.150 \%$ & $0.036 \%$ & $0.017 \%$ & $-0.160 \%$ & $0.076 \%$ & $0.586 \%$ & $-0.051 \%$ & $0.543 \%$ & $0.546 \%$ \\
\hline Italy & $0.286 \%$ & $0.009 \%$ & $-0.268 \%$ & $0.341 \%$ & $1.340 \%$ & $1.338 \%$ & $1.203 \%$ & $-0.070 \%$ & $0.044 \%$ & $0.028 \%$ & $0.040 \%$ & $0.025 \%$ & $0.494 \%$ & $0.169 \%$ & $0.133 \%$ & $0.377 \%$ \\
\hline Spain & $0.285 \%$ & $0.297 \%$ & $0.309 \%$ & $0.328 \%$ & $0.672 \%$ & $0.637 \%$ & $0.444 \%$ & $0.008 \%$ & $0.086 \%$ & $0.056 \%$ & $-0.005 \%$ & $0.076 \%$ & $0.292 \%$ & $-0.105 \%$ & $0.471 \%$ & $0.409 \%$ \\
\hline Japan & $0.201 \%$ & $0.158 \%$ & $0.114 \%$ & $0.502 \%$ & $18.301 \%$ & $-1.463 \%$ & $0.101 \%$ & $0.091 \%$ & $0.011 \%$ & $0.007 \%$ & $0.116 \%$ & $0.232 \%$ & $0.221 \%$ & $0.152 \%$ & $-1.787 \%$ & $0.671 \%$ \\
\hline UK & $0.268 \%$ & $0.277 \%$ & $0.285 \%$ & $0.294 \%$ & $-0.319 \%$ & $-0.319 \%$ & $-0.629 \%$ & $-0.036 \%$ & $0.019 \%$ & $0.003 \%$ & $0.115 \%$ & $0.138 \%$ & $0.281 \%$ & $-0.075 \%$ & $-1.219 \%$ & $0.391 \%$ \\
\hline Canada & $0.336 \%$ & $0.439 \%$ & $0.542 \%$ & $0.296 \%$ & $1.243 \%$ & $1.206 \%$ & $0.581 \%$ & $0.034 \%$ & $0.031 \%$ & $0.007 \%$ & $-0.061 \%$ & $0.135 \%$ & $0.229 \%$ & $-0.002 \%$ & $0.563 \%$ & $0.327 \%$ \\
\hline Switzerland & $0.238 \%$ & $0.253 \%$ & $0.267 \%$ & $0.303 \%$ & $-0.424 \%$ & $-0.736 \%$ & $-1.953 \%$ & $0.029 \%$ & $0.007 \%$ & $0.009 \%$ & $-0.011 \%$ & $0.099 \%$ & $-2.048 \%$ & $0.198 \%$ & $0.274 \%$ & $-4.595 \%$ \\
\hline US & $0.297 \%$ & $0.436 \%$ & $0.574 \%$ & $0.616 \%$ & $7.000 \%$ & $2.767 \%$ & $1.120 \%$ & $-0.012 \%$ & $-0.008 \%$ & $-0.008 \%$ & $0.212 \%$ & $0.339 \%$ & $1.417 \%$ & $0.058 \%$ & $0.588 \%$ & $-12.211 \%$ \\
\hline
\end{tabular}

${ }^{60}$ The constraints with respect to slope; slope and curve; and level, slope, and curve follow S, S-C, and L-S-C. 
Table 6

BAB Trading Strategies: 11 Government Bond Markets: Bloomberg and MSCI Data

Lag Length (Months): (36)

Note: Beta Shrinkage follows Vasicek (1973)

Sharpe Ratios

\begin{tabular}{|c|c|c|c|c|c|c|c|c|c|c|c|c|c|c|c|c|}
\hline \multirow{2}{*}{$\begin{array}{l}\text { Constraint: } \\
\text { Non-Linear? } \\
\text { Beta w.r.t. (Market) }\end{array}$} & \multirow[b]{2}{*}{ Gov. } & \multirow[b]{2}{*}{ Gov.\&Equ } & \multirow[b]{2}{*}{ Equ. } & \multirow[b]{2}{*}{$\mathrm{BAB}(\mathrm{F} \& \mathrm{P})$} & \multirow{2}{*}{$\begin{array}{l}\text { None } \\
\text { N/A } \\
\text { Gov. }\end{array}$} & \multirow{2}{*}{$\begin{array}{c}\text { Equ. } \\
\text { No } \\
\text { Gov.\&Equ }\end{array}$} & \multirow{2}{*}{$\begin{array}{l}\text { Equ. } \\
\text { No } \\
\text { Equ. }\end{array}$} & \multirow{2}{*}{$\begin{array}{c}\text { S } \\
\text { No } \\
\text { Gov. }\end{array}$} & \multirow{2}{*}{$\begin{array}{l}\text { S-C } \\
\text { No } \\
\text { Gov. }\end{array}$} & \multirow{2}{*}{$\begin{array}{c}\text { L-S-C } \\
\text { No } \\
\text { Gov. }\end{array}$} & \multirow{2}{*}{$\begin{array}{c}\text { Gamma } \\
\text { No } \\
\text { Gov. }\end{array}$} & \multirow{2}{*}{$\begin{array}{c}\text { Gamma } \\
\text { Yes } \\
\text { Gov. }\end{array}$} & \multirow{2}{*}{$\begin{array}{c}\text { Beta_SKD } \\
\text { No } \\
\text { Gov } \\
\end{array}$} & \multirow{2}{*}{$\begin{array}{c}\text { Gamma } \\
\text { No } \\
\text { Gov.\&Equ }\end{array}$} & \multirow{2}{*}{$\begin{array}{c}\text { Gamma } \\
\text { Yes } \\
\text { Gov.\&Equ }\end{array}$} & \multirow{2}{*}{$\begin{array}{c}\text { Beta_SKD } \\
\text { No } \\
\text { Gov.\&Equ. }\end{array}$} \\
\hline & & & & & & & & & & & & & & & & \\
\hline Germany & 0.227 & 0.126 & 0.072 & 0.193 & 0.225 & 0.201 & 0.156 & -0.049 & -0.113 & -0.108 & -0.014 & 0.232 & 0.202 & 0.191 & 0.240 & 0.118 \\
\hline France & 0.239 & 0.145 & 0.080 & 0.236 & 0.222 & 0.220 & 0.154 & 0.076 & -0.010 & 0.010 & 0.069 & 0.119 & 0.062 & 0.067 & 0.068 & 0.062 \\
\hline Netherlands & 0.229 & 0.149 & 0.088 & 0.222 & 0.315 & 0.306 & 0.253 & 0.051 & -0.067 & -0.071 & -0.025 & 0.194 & 0.154 & 0.073 & 0.194 & 0.220 \\
\hline Belgium & 0.196 & 0.085 & 0.038 & 0.165 & 0.256 & 0.307 & 0.087 & 0.116 & 0.064 & 0.057 & -0.200 & 0.181 & 0.146 & -0.071 & 0.165 & 0.134 \\
\hline Italy & 0.164 & 0.003 & -0.047 & 0.182 & 0.289 & 0.289 & 0.332 & -0.068 & 0.069 & 0.063 & 0.043 & 0.029 & 0.177 & 0.164 & 0.084 & 0.146 \\
\hline Spain & 0.142 & 0.087 & 0.051 & 0.139 & 0.150 & 0.143 & 0.110 & 0.005 & 0.106 & 0.122 & -0.006 & 0.157 & 0.141 & -0.091 & 0.159 & 0.185 \\
\hline Japan & 0.237 & 0.062 & 0.022 & 0.159 & 0.112 & -0.107 & 0.137 & 0.118 & 0.024 & 0.026 & 0.050 & 0.118 & 0.034 & 0.109 & -0.047 & 0.055 \\
\hline UK & 0.181 & 0.132 & 0.071 & 0.144 & -0.006 & -0.006 & -0.012 & -0.017 & 0.042 & 0.009 & 0.096 & 0.128 & 0.094 & -0.086 & -0.069 & 0.159 \\
\hline Canada & 0.230 & 0.184 & 0.119 & 0.202 & 0.283 & 0.276 & 0.263 & 0.050 & 0.090 & 0.029 & -0.088 & 0.149 & 0.169 & -0.003 & 0.274 & 0.212 \\
\hline Switzerland & 0.206 & 0.107 & 0.057 & 0.175 & -0.008 & -0.013 & -0.124 & 0.035 & 0.015 & 0.022 & -0.013 & 0.122 & -0.068 & 0.121 & 0.146 & -0.068 \\
\hline US & 0.161 & 0.196 & 0.129 & 0.353 & 0.116 & 0.050 & 0.288 & -0.013 & -0.015 & -0.022 & 0.158 & 0.207 & 0.169 & 0.047 & 0.274 & -0.055 \\
\hline
\end{tabular}


Table 7

\section{BAB Unconstrained and Contrained Strategies: Coskew U.S. Treasury Market: CRSP Data}

\begin{tabular}{|c|c|c|c|c|}
\hline Return Frequency & Daily & Daily & Monthly & Monthly \\
\hline Lags (Months) & 11 & 35 & 11 & 59 \\
\hline Beta Shrinkage based on Vasicek (1973)? & Yes & Yes & Yes & Yes \\
\hline Sample Begin & $05 / 1962$ & 05/1964 & $05 / 1962$ & $05 / 1966$ \\
\hline Sample End & $12 / 2013$ & $12 / 2013$ & $12 / 2013$ & $12 / 2013$ \\
\hline Observations & 620 & 596 & 616 & 568 \\
\hline Stock Market Sharpe Ratio & 0.12249 & 0.18609 & 0.1133 & 0.19756 \\
\hline Gov. Bond Market Sharpe Ratio & 0.12668 & 0.20757 & 0.10838 & 0.21929 \\
\hline BAB [F\&P 2014] Sharpe Ratio & 0.36728 & 1.0089 & 0.16216 & 0.97663 \\
\hline \multicolumn{5}{|l|}{ Unconstrained } \\
\hline Mean Beta Long Side & 0.32666 & 0.20096 & 0.15243 & 0.15495 \\
\hline Mean Beta Short Side & 2.1679 & 2.221 & 2.0624 & 2.1652 \\
\hline Excess Return & $0.018 \%$ & $0.106 \%$ & $0.504 \%$ & $2.938 \%$ \\
\hline Sharpe Ratio & 0.31779 & 1.2702 & 0.2833 & 1.2629 \\
\hline \multicolumn{5}{|c|}{ Gamma Constrained Gov. Bonds (Non-linear) } \\
\hline Mean Beta Long Side & 0.77844 & 0.77932 & 0.63009 & 0.66454 \\
\hline Mean Beta Short Side & 1.2783 & 1.2605 & 1.2813 & 1.355 \\
\hline Excess Return & $0.004 \%$ & $0.012 \%$ & $0.112 \%$ & $0.455 \%$ \\
\hline Sharpe Ratio & 0.15307 & 0.40187 & 0.11483 & 0.54961 \\
\hline \multicolumn{5}{|l|}{ Gamma Constrained Gov. Bonds (Linear) } \\
\hline Mean Beta Long Side & 0.97447 & 0.93137 & 1.1856 & 0.85604 \\
\hline Mean Beta Short Side & 2.074 & 1.3911 & 1.8294 & 1.6428 \\
\hline Excess Return & $0.012 \%$ & $0.017 \%$ & $-0.016 \%$ & $0.579 \%$ \\
\hline Sharpe Ratio & 0.41334 & 0.57945 & -0.025849 & 0.62142 \\
\hline \multicolumn{5}{|l|}{ Beta SKD Constrained Gov. Bonds (Linear) } \\
\hline Mean Beta Long Side & 0.60269 & 0.53567 & 0.56246 & 0.56521 \\
\hline Mean Beta Short Side & 1.8618 & 1.9299 & 1.8129 & 1.8895 \\
\hline Excess Return & $0.009 \%$ & $0.043 \%$ & $0.142 \%$ & $0.777 \%$ \\
\hline Sharpe Ratio & 0.28 & 0.85695 & 0.2011 & 0.70272 \\
\hline \multicolumn{5}{|c|}{ Gamma Constrained Gov. Bonds \& Equities (Non-linear) } \\
\hline Mean Beta Long Side & 0.96135 & 0.66194 & 0.52029 & 0.7209 \\
\hline Mean Beta Short Side & 1.2351 & 0.99605 & 1.0526 & 1.2447 \\
\hline Excess Return & $0.004 \%$ & $0.013 \%$ & $0.063 \%$ & $0.290 \%$ \\
\hline Sharpe Ratio & 0.20156 & 0.40301 & 0.1013 & 0.55156 \\
\hline \multicolumn{5}{|c|}{ Gamma Constrained Gov. Bonds \& Equities (Linear) } \\
\hline Mean Beta Long Side & 0.41151 & 0.76767 & 0.7467 & 0.70265 \\
\hline Mean Beta Short Side & 1.8914 & 1.5556 & 1.4638 & 1.5449 \\
\hline Excess Return & $0.017 \%$ & $0.016 \%$ & $0.060 \%$ & $0.497 \%$ \\
\hline Sharpe Ratio & 0.36626 & 0.40505 & 0.090194 & 0.59648 \\
\hline \multicolumn{5}{|c|}{ Beta SKD Constrained Gov. Bonds \& Equities (Linear) } \\
\hline Mean Beta Long Side & 0.5676 & 0.57371 & 0.55835 & 0.59495 \\
\hline Mean Beta Short Side & 1.6752 & 1.666 & 1.6278 & 1.6812 \\
\hline Excess Return & $0.010 \%$ & $0.029 \%$ & $0.148 \%$ & $0.633 \%$ \\
\hline Sharpe Ratio & 0.28905 & 0.65618 & 0.14268 & 0.68371 \\
\hline
\end{tabular}


Table 8

Three-moment CAPM Asset-Pricing Tests

U.S. Treasury Market: CRSP Data

\begin{tabular}{|c|c|c|c|c|c|c|}
\hline Return Frequency & Daily & Daily & Daily & Monthly & Monthly & Monthly \\
\hline Lags (Months) & 11 & 35 & 13050 & 11 & 59 & 626 \\
\hline Beta Shrinkage based on Vasicek (1973)? & Yes & Yes & Yes & Yes & Yes & Yes \\
\hline Sample Begin & $05 / 1962$ & $05 / 1964$ & $12 / 2013$ & $05 / 1962$ & $05 / 1966$ & $12 / 2013$ \\
\hline Sample End & $12 / 2013$ & $12 / 2013$ & $12 / 2013$ & $12 / 2013$ & $12 / 2013$ & $12 / 2013$ \\
\hline Observations & 620 & 596 & 1 & 616 & 568 & 1 \\
\hline Alpha (Gov. Bonds [K\&L 1976]) & 0.00009 & 0.00024 & 0.00003 & 0.00054 & 0.00477 & 0.00050 \\
\hline t stat $[\mathrm{F} \& M$ 1973] & 0.29347 & 0.80666 & 0.33333 & 0.11111 & 0.77790 & 0.33333 \\
\hline Lambda_Beta (Gov. Bonds [K\&L 1976]) & 0.00004 & 0.00004 & 0.00000 & 0.00076 & 0.00079 & 0.00007 \\
\hline t stat $[\mathrm{F} \& M$ 1973] & 0.06251 & 0.05778 & 0.33333 & 0.05541 & 0.05672 & 0.33333 \\
\hline R-Squared & 0.67274 & 0.69071 & 0.10013 & 0.65009 & 0.69387 & 0.10658 \\
\hline Alpha (Gov. Bonds [K\&L 1976]) & 0.00009 & 0.00028 & 0.00002 & 0.00057 & 0.00478 & 0.00048 \\
\hline t stat [F\&M 1973] & 0.20221 & 0.15446 & 0.33333 & 0.08858 & 0.18172 & 0.33333 \\
\hline Lambda_Beta (Gov. Bonds [K\&L 1976]) & 0.00004 & 0.00005 & 0.00000 & 0.00129 & 0.00065 & 0.00005 \\
\hline t stat [F\&M 1973] & 0.06594 & 0.07124 & -0.33333 & 0.06850 & 0.04216 & 0.33333 \\
\hline Lambda_Gamma (Gov. Bonds [K\&L 1976]) & -0.00001 & -0.00002 & 0.00000 & 0.00095 & 0.00000 & 0.00004 \\
\hline t stat [F\&M 1973] & -0.02259 & -0.00817 & 0.33333 & 0.03784 & 0.00000 & 0.33333 \\
\hline R-Squared & 0.70034 & 0.73456 & 0.10866 & 0.77605 & 0.76746 & 0.10702 \\
\hline Alpha (Gov. Bonds [C\&S 2000]) & 0.00009 & 0.00023 & 0.00002 & 0.00081 & 0.00495 & 0.00049 \\
\hline t stat [F\&M 1973] & 0.34305 & 0.77712 & 0.33333 & 0.14921 & 0.71062 & 0.33333 \\
\hline Lambda_Beta (Gov. Bonds [C\&S 2000] & 0.00003 & 0.00004 & 0.00000 & 0.00047 & 0.00059 & 0.00008 \\
\hline t stat [F\&M 1973] & 0.06250 & 0.06367 & 0.33333 & 0.03884 & 0.04544 & 0.33333 \\
\hline Lambda_BetaSKD [Gov. Bonds [C\&S 2000] & -0.00002 & -0.00001 & 0.00003 & 0.00019 & 0.00038 & 0.00002 \\
\hline t stat [F\&M 1973] & -0.01201 & -0.00585 & 0.33333 & 0.01560 & 0.02155 & 0.33333 \\
\hline R-Squared & 0.76601 & 0.77672 & 0.10577 & 0.78848 & 0.80921 & 0.10666 \\
\hline
\end{tabular}


Table 9

Three-moment CAPM Asset-Pricing Tests

U.S. Treasury Market: CRSP Data

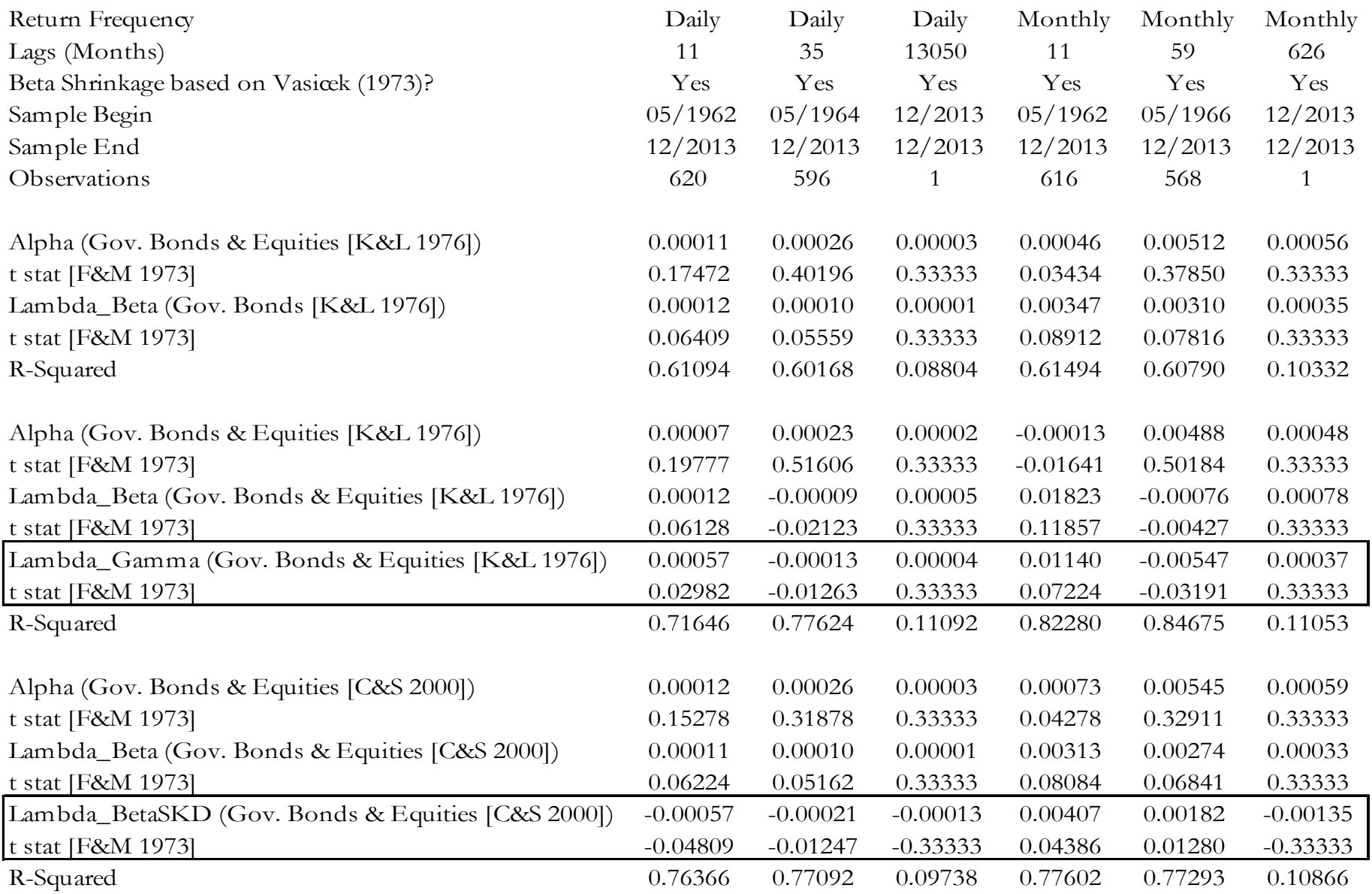


Figure 1

Betting Against Beta: U.S. Treasuries: CRSP Data (Daily) (05/28/1964-12/31/2013)

$$
\text { Lag Length (Months) = (36) }
$$

BAB Sharpe Ratio (1.0089), Market Sharpe Ratio (0.47461)

BAB Sharpe Ratio: (01/31/1992-12/31/2013) (0.73965)

$\times 10^{-3} \quad$ Note: Beta Shrinkage follows Vasicek (1973)

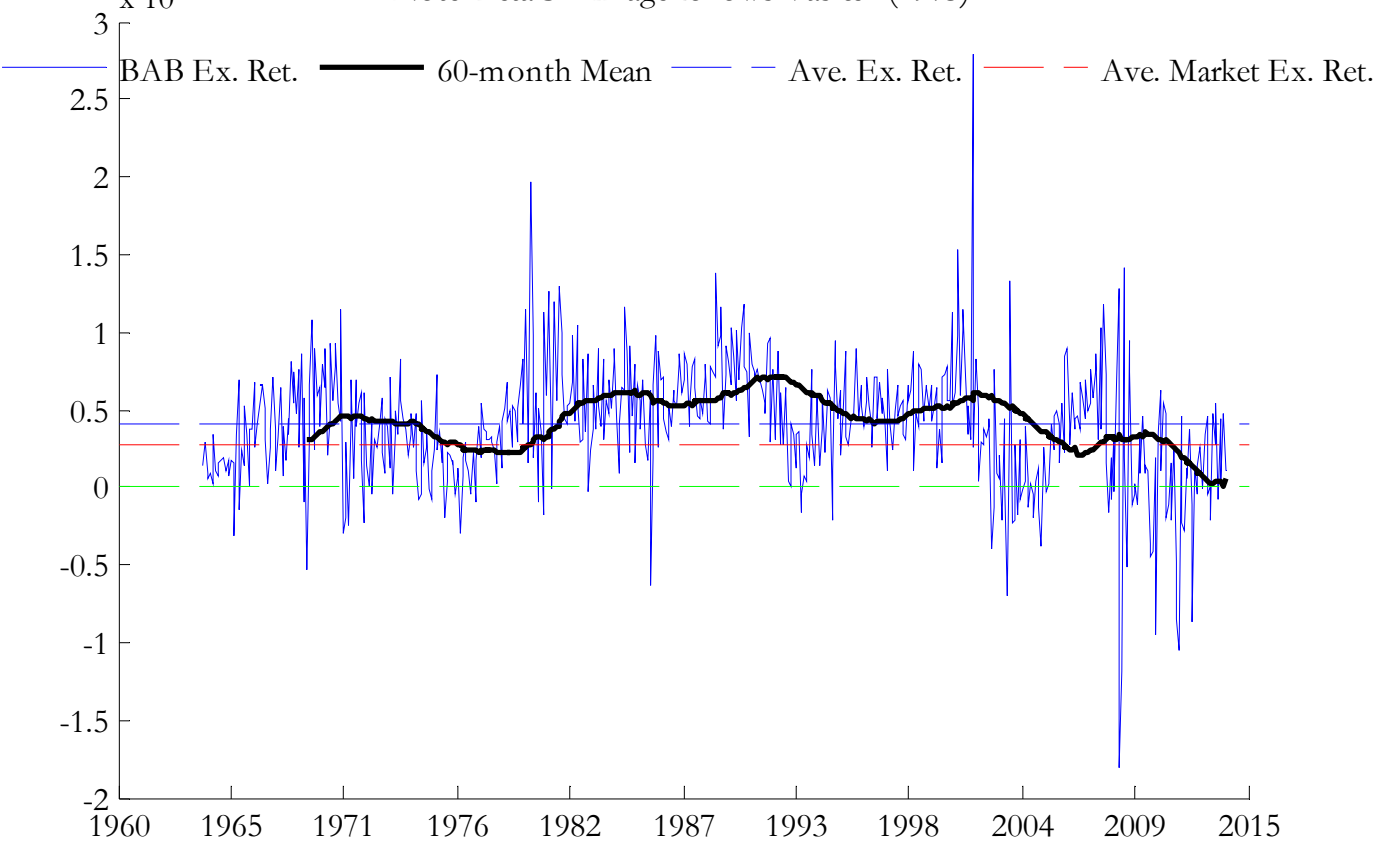

Figure 2

Surface of Sharpe Ratios and Maturity

11 Government Bond Markets

GR(1) FR(2) NE(3) BE(4) IT(5) SP(6) JN(7) UK(8) CA(9) SZ(10) US(11)

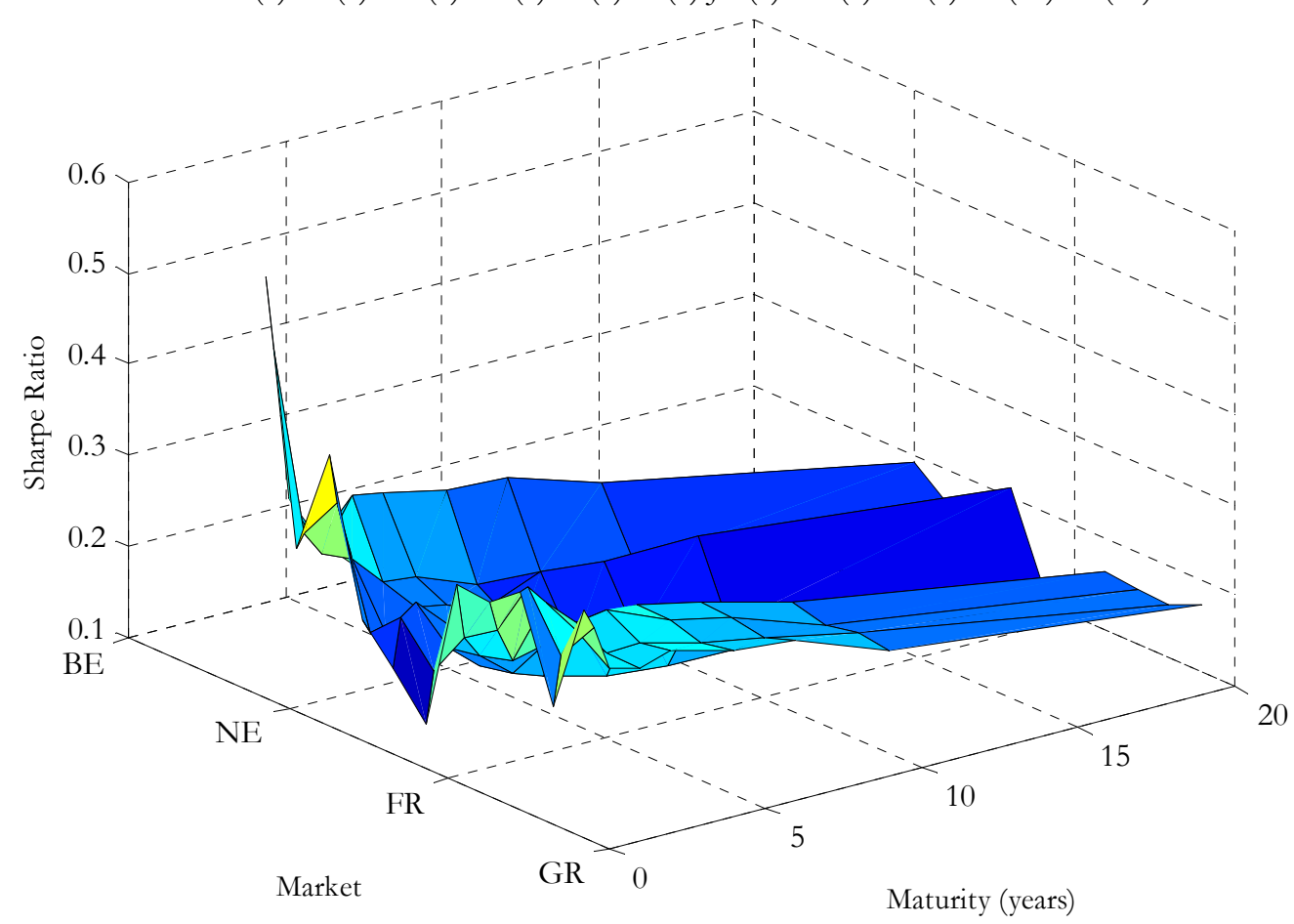

Figure 3 
Sharpe Ratio Schedules: Selected Government Bond Market (Estimates based on Bloomberg data)

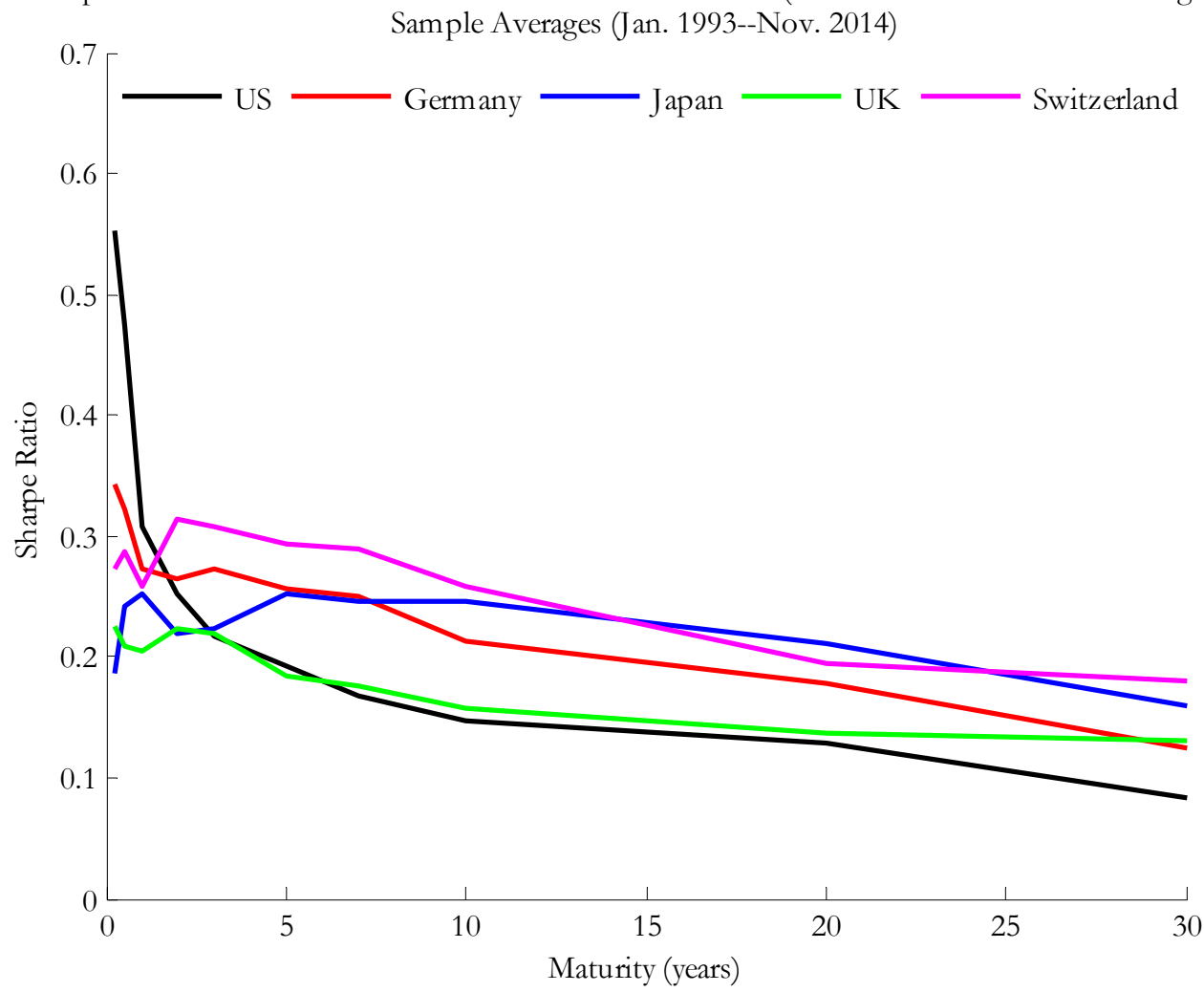

Figure 4

U.S. (CRSP): Betting Against Gamma (Daily) (05/28/1964-12/31/2013) BAG: F\&P (2014) Method

BAG Sharpe Ratio (0.011017), Market Sharpe Ratio (0.47461)

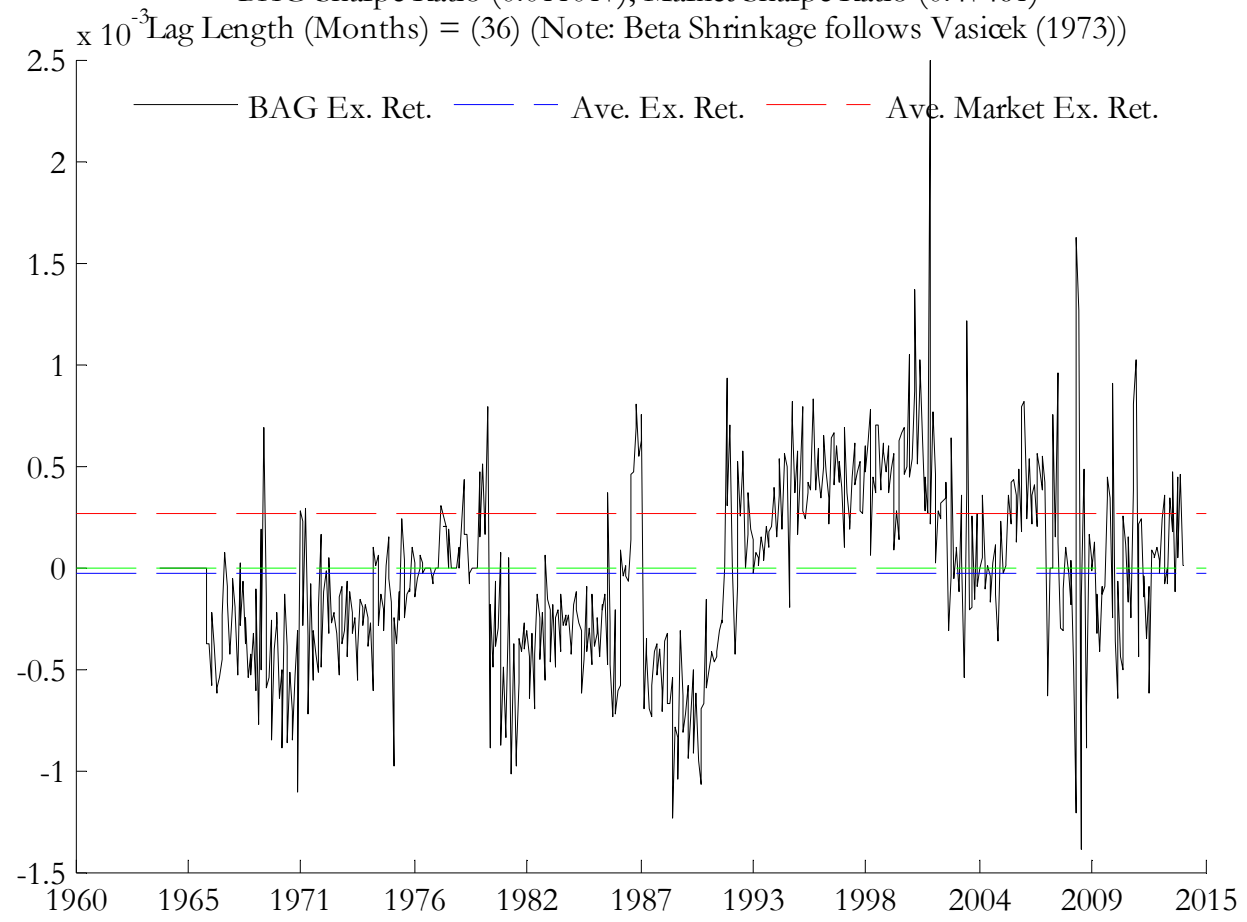

Figure 5 
U.S. (CRSP): Betting Against Gamma (Daily) (05/28/1964-12/31/2013)

BAG (BetaSKD): F\&P (2014) Method

BAG Sharpe Ratio (0.015763), Market Sharpe Ratio (0.47461)

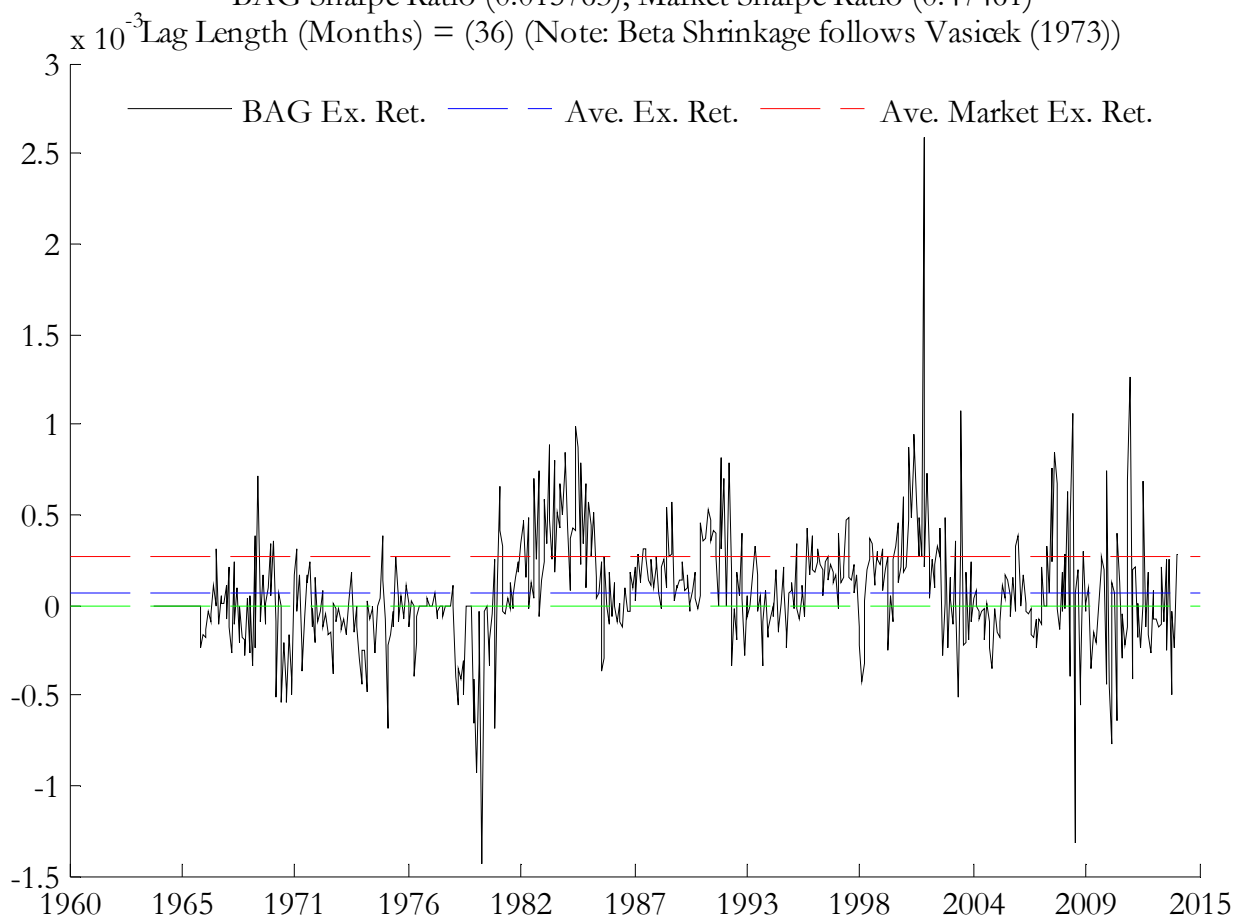

Figure 6

Betting Against Beta: U.S. Treasuries: CRSP Data (Monthy) (06/30/1961-12/31/2013)

Lag Length (Months) $=(627)$

Market Proxy: USTs

Note: Beta Shrinkage follows Vasicek (1973)

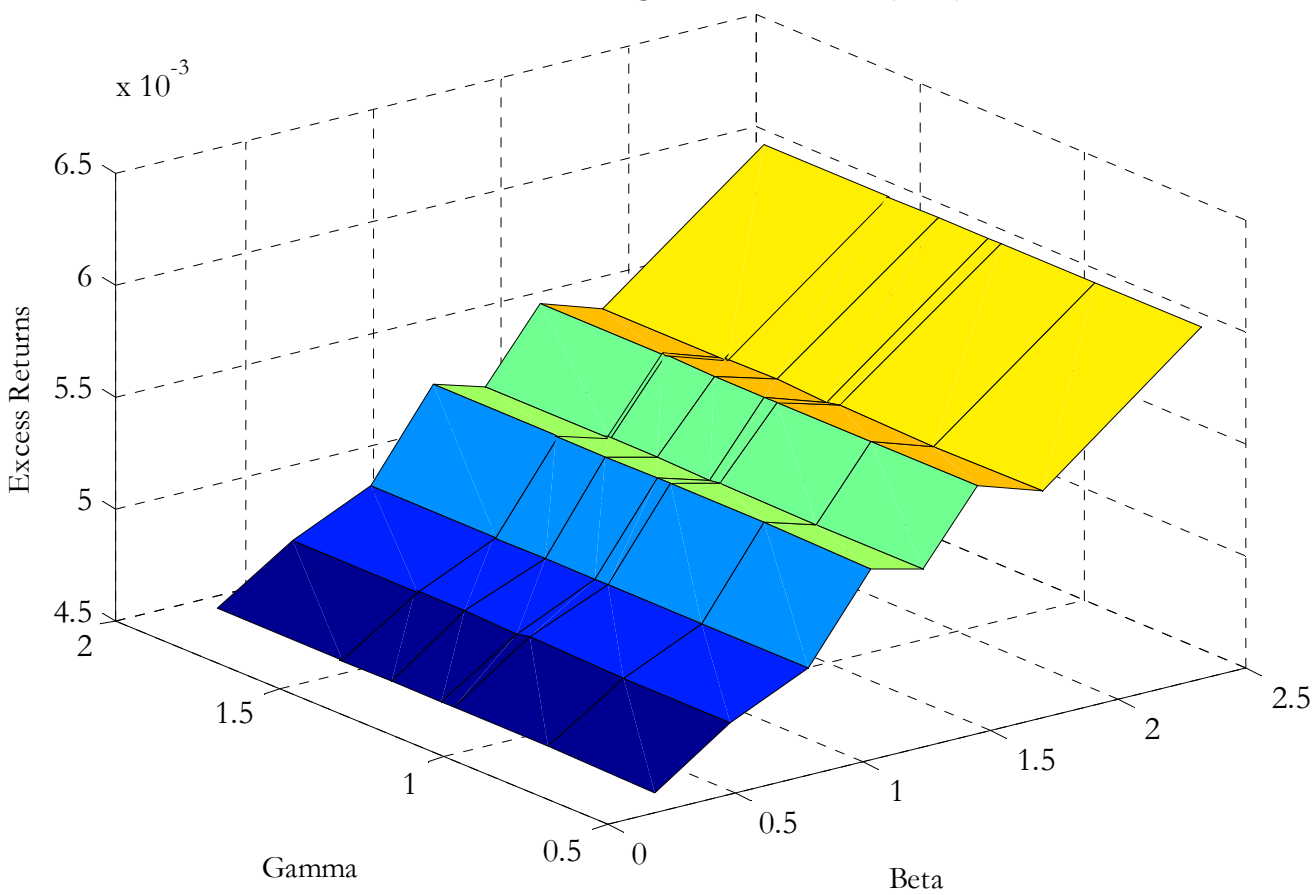

Figure 7 
Betting Against Beta: U.S. Treasuries: CRSP Data (Monthy) (06/30/1961-12/31/2013)

Lag Length (Months) $=(627)$

Market Proxy: USTs\&Equities

Note: Beta Shrinkage follows Vasicek (1973)

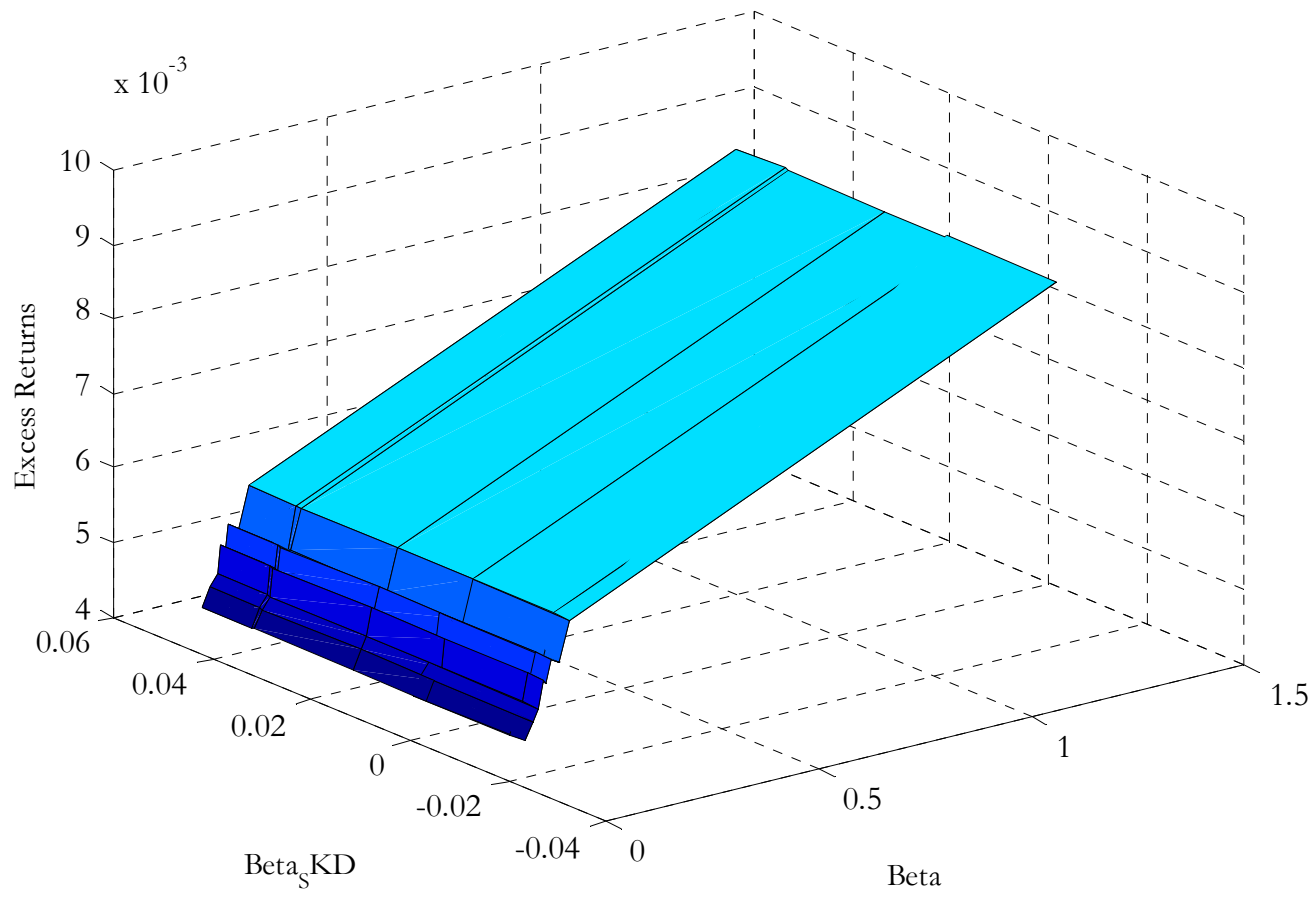




\section{Appendix 1: GATSM-implied Sharpe Ratios}

Although Duffee (2010) finds, notably empirically, an inverse relation SRs and maturity, that relation need not be so analytically. Consider a rudimentary, single-factor, short-rate affine model framework with

$$
P(r, \tau)=\exp [A-B r]
$$

where $A$ and $B$ are functions of maturity, $\tau$, and $r$ is the observed instantaneous short rate. Now define the Sharpe ratio (informally) as the expected excess return, or the (zero-coupon) term premium, scaled by the standard deviation of returns, as in

$$
S R \approx \frac{-\frac{1}{\tau}(A-B r)-\frac{1}{\tau} \int_{0}^{\tau} E\left[r_{s}\right] d s}{\sqrt{V A R\left(\frac{d P}{P}\right)}}
$$

To examine a tractable expression for the SR, under the Merton model, the short rate follows $d r=\mu d t+\sigma d W$, and therefore

$$
\frac{1}{\tau} \int_{0}^{\tau} E\left[r_{s}\right] d s=r+\frac{1}{2} \mu \tau
$$

Also, following Ito's lemma,

$$
\frac{d P}{P}=\frac{\left(\frac{\partial P}{\partial \tau}+\mu \frac{\partial P}{\partial r}+\frac{1}{2} \sigma^{2} \frac{\partial^{2} P}{\partial r^{2}}\right) d t}{P}+\frac{\sigma \frac{\partial P}{\partial r} d W}{P}
$$

And thus under the affine solution, namely with $\frac{\partial P}{\partial r}=-P B$, the second term the captures the standard deviation of returns, as in

$$
\sqrt{V A R\left(\frac{d P}{P}\right)}=-\sigma B
$$

Given the solution to the Merton model, ${ }^{61}$ the expression for the Sharpe ratio (SR) follows

$$
\begin{aligned}
S R & \approx \frac{\frac{1}{\tau}\left(-\frac{\tau^{2}}{2}(\mu-\lambda \sigma)+\frac{1}{6} \sigma^{2} \tau^{3}-\tau r\right)+\left(r+\frac{1}{2} \mu \tau\right)}{\sigma \tau} \\
& \approx \frac{1}{2} \lambda+\frac{1}{6} \sigma \tau
\end{aligned}
$$

${ }^{61}$ See, say, Baz and Chacko (2004), pg. 136. 
Recall that profitable $\mathrm{BAB}$ trading strategies reflect the empirical regularity that the security market line is too flat, and in turn as well as in the case of bonds that SRs decrease as maturity or beta increases. Note that with affine-model-based solutions for bond prices, we can examine this relation in closed form. For example, under the Merton model, the slope of the SR w.r.t. maturity (or duration or beta), follows

$$
\frac{\partial}{\partial \tau} S R=\frac{1}{6} \sigma
$$

Therefore, in direct contrast to the required conditions for BAB, in this very restricted model at least the schedule of SRs is always upward-sloping in maturity (or duration or beta), only a function of volatility, and cannot be an artefact of parameter estimation. ${ }^{62}$ Also, that that the market price of risk, which might subsume investors' (time-varying) leverage constraints, cannot affect the tradeoff between SRs and beta in the Merton model.

Consider also some partial derivatives with respect to the volatility and market price of risk parameters. In addition, as volatility increases, the returns to BAB decrease, as the tradeoff between SR and beta increases, as

$$
\frac{\partial}{\partial \sigma}\left(\frac{\partial}{\partial \tau} S R\right)=\frac{1}{6}
$$

${ }^{62}$ Of course, this restriction may be just one of many reasons why the Merton model does not satisfactorily fit the data. 


\section{Appendix 2: Some Rudiments of Skew and Coskew Measures}

Similar to the beta, $\beta$, of an asset and portfolio variance, the gamma of an asset, $\gamma$, is the scaled marginal contribution to portfolio skew, with $w$ is weight of asset $i$ in the portfolio following

$$
\begin{aligned}
\frac{\partial}{\partial w_{i}} E\left\{\left(r_{m}-\mu_{m}\right)^{3}\right\} & =\frac{\partial}{\partial w_{i}} E\left\{\left[\sum_{i} w_{i} r_{i}-\sum_{i} w_{i} \mu_{i}\right]^{3}\right\} \\
& =\frac{\partial}{\partial w_{i}} E\left\{\left[\sum_{i} w_{i}\left(r_{i}-\mu_{i}\right)\right]^{3}\right\} \\
& =E\left\{3\left[\sum_{i} w_{i}\left(r_{i}-\mu_{i}\right)\right]^{2}\left(r_{i}-\mu_{i}\right)\right\} \\
& =3 E\left\{\left(r_{m}-\mu_{m}\right)^{2}\left(r_{i}-\mu_{i}\right)\right\} \\
& =3 \operatorname{cov}\left\{r_{i}\left(r_{m}-\mu_{m}\right)^{2}\right\}+3 E\left\{\left(r_{m}-\mu_{m}\right)^{2}\right\} E\left\{r_{i}-\mu_{i}\right\}
\end{aligned}
$$

Given that $E\left\{r_{i}-\mu_{i}\right\}=0$, and scaling by $\frac{1}{3 E\left\{\left(r_{m}-\mu_{m}\right)^{3}\right\}}$ to ensure that market co-skew equals one, follows

$$
\gamma_{i}=\frac{\operatorname{cov}\left\{r_{i}\left(r_{m}-\mu_{m}\right)^{2}\right\}}{E\left\{\left(r_{m}-\mu_{m}\right)^{3}\right\}}
$$

Note also the $\beta$ and $\gamma$ can be derived from the coefficients in the following regression (and taking expectations), as in

$$
\begin{aligned}
& r_{i, t}=c_{0 i}+c_{1 i} r_{m, t}+c_{2 i}\left(r_{m, t}-\mu_{m}\right)^{2}+\tilde{e}_{i} \\
& E\left[r_{i, t}\right]=c_{0 i}+c_{1 i} \mu_{m}+c_{2 i} E\left[\left(r_{m, t}-\mu_{m}\right)^{2}\right]+0
\end{aligned}
$$

Taking differences and multiplying through by $\left(r_{m, t}-\mu_{m}\right)$ follows

$$
\begin{aligned}
\left(r_{m, t}-\mu_{m}\right)\left(r_{i, t}-E\left[r_{i, t}\right]\right) & =\left(r_{m, t}-\mu_{m}\right)\left\{c_{1 i}\left(r_{m, t}-\mu_{m}\right)+c_{2 i}\left(\left(r_{m, t}-\mu_{m}\right)^{2}-E\left[\left(r_{m, t}-\mu_{m}\right)^{2}\right]\right)\right\} \\
& =c_{1 i}\left(r_{m, t}-\mu_{m}\right)^{2}+c_{2 i}\left(\left(r_{m, t}-\mu_{m}\right)^{3}-\left(r_{m, t}-\mu_{m}\right) E\left[\left(r_{m, t}-\mu_{m}\right)^{2}\right]\right)
\end{aligned}
$$

Again, taking expectations and noting that $E\left[\left(r_{m, t}-\mu_{m}\right)\right]$, as in 


$$
\begin{aligned}
E\left[\left(r_{m, t}-\mu_{m}\right)\left(r_{i, t}-E\left[r_{i, t}\right]\right)\right] & =c_{1 i} E\left[\left(r_{m, t}-\mu_{m}\right)^{2}\right]+c_{2 i} E\left[\left(r_{m, t}-\mu_{m}\right)^{3}-\left(r_{m, t}-\mu_{m}\right) E\left[\left(r_{m, t}-\mu_{m}\right)^{2}\right]\right] \\
& =c_{1 i} E\left[\left(r_{m, t}-\mu_{m}\right)^{2}\right]+c_{2 i}\left(E\left[\left(r_{m, t}-\mu_{m}\right)\right]^{3}-(0) E\left[\left(r_{m, t}-\mu_{m}\right)^{2}\right]\right)
\end{aligned}
$$

Therefore

$$
\begin{aligned}
\operatorname{cov}\left(r_{m}, r_{i}\right) & =c_{1 i} \sigma_{r_{m}}^{2}+c_{2 i} \mathbf{M}_{r_{m}}^{3} \\
\beta_{i} & =c_{1 i}+c_{2 i} \frac{\mathbf{M}_{r_{m}}^{3}}{\sigma_{r_{m}}^{2}}
\end{aligned}
$$

For $\gamma$, multiplying through by $\left(r_{m, t}-\mu_{m}\right)^{2}$, and again taking expectations leads to

$$
\begin{aligned}
E\left[\left(r_{m, t}-\mu_{m}\right)^{2}\left(r_{i, t}-E\left[r_{i, t}\right]\right)\right] & =c_{1 i} E\left[\left(r_{m, t}-\mu_{m}\right)^{3}\right]+c_{2 i} E\left[\left(r_{m, t}-\mu_{m}\right)^{4}-\left(r_{m, t}-\mu_{m}\right)^{2} E\left[\left(r_{m, t}-\mu_{m}\right)^{2}\right]\right] \\
\operatorname{cov}\left(r_{i}, \mathbf{r}_{m}^{2}\right) & =c_{1 i} \mathbf{M}_{r_{m}}^{3}+c_{2 i}+c_{2 i}\left(E\left[\left(r_{m, t}-\mu_{m}\right)^{4}\right]-E\left[\left(r_{m, t}-\mu_{m}\right)^{2}\right] E\left[\left(r_{m, t}-\mu_{m}\right)^{2}\right]\right)
\end{aligned}
$$

And therefore,

$$
\gamma_{i}=c_{1 i}+c_{2 i} \frac{\mathbf{M}_{r_{m}}^{4}-\sigma_{r_{m}}^{4}}{\mathbf{M}_{r_{m}}^{3}}
$$

In addition to $\gamma$, a second measure of co-skew, follows Harvey and Siddique (2000, pg. 1276), as in

$$
\hat{\beta}_{S K D_{i}}=\frac{E\left\{\varepsilon_{i, t+1} \varepsilon_{M, t+1}^{2}\right\}}{\sqrt{E\left\{\varepsilon_{i, t+1}\right\}} \sqrt{E\left\{\varepsilon_{M, t+1}^{2}\right\}}}
$$

where $\varepsilon_{i, t+1}=r_{i, t+1}-\alpha_{i}+\beta_{i}\left(r_{M, t+1}\right)$, i.e., the residual of the regression of excess return on the contemporaneous market return.

Finally, Bowley skew, $S_{B}$, follows

$$
S_{B}=\frac{P(0.75)+P(0.25)-2 P(50)}{P(0.75)-P(0.25)}
$$

where $P(\tau)$ is the $\tau^{\text {th }}$ sample quantile. 